\author{
ANL/NDII -59
}

DE82 009833

\author{
ANL/NDM-59 \\ Review of the Neutron-Capture Process in \\ Fission Reactors \\ by \\ W. P. Poentitz \\ Ju1y 1981
}

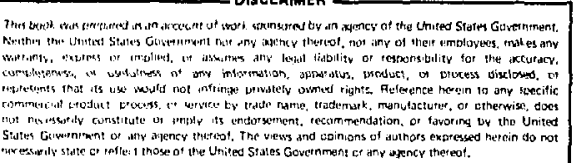

PORTIONS OF THIS FEPORT ARE ILHEGIPLE. has been reproduced from the best availablo copy to permit the broadest possiblo availab111ty.

Applied Physics Division

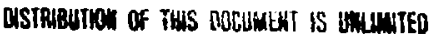
Argonne National Laboratory 9700 South Cass Avenue Argonne, Illinois 60439 
The Nuclear Data and Measurements Series presents results of studies in the field of microscopic nuclear data. The primary objective is the dissemination of information in the comprehensive form required for nuclear technology applications. This Series is devoted to: a) measured microscopic nuclear parameters, b) experimental techniques and factlities employed in measurements, c) the analysis, correlation and interpretation of nuclear data, and d) the evaluation of nuclear data. Contributions to this Series are reviewed to assure technical competence and, unless otherwise stated, the contents can be formally referenced. This Series does not supplant formal journal publication but it does provide the more extensive information required for technological applications (e.g., tabulated numerical data) in a timely manner. 
OTHER ISSUES IN THE ANL/NDM SERIES ARE:

ANL/NDM-1 Cobalt Fast Neutron Cross Sections-Measurement and Evaluation by P. T. Guenther, P. A. Moldauer, A. B. Smith, D. L. Smith and J. F. Whalen, July 1973.

ANL/NDM-2 Prompt Air-Scattering Corrections for a Fast-Neutron Fission Detector: $\mathrm{E}_{\mathbf{n}} \leq 5 \mathrm{MeV}$ by Donald L. Smith, September 1973.

ANL/NDM-3 Neutron Scattering from Titanium; Compound and Direct Effects by E. Barnard, J. deVilliers, P. Moldauer, D. Reitmann, A. Suith and $J$. Whalen, October 1973.

ANL/NDM-4 $\quad{ }^{90} \mathrm{Zr}$ and ${ }^{92} \mathrm{Zr}$; Neutron Total and Scattering Cross Sections by P. Guenther, A. Smith and J. Whalen, July 1974.

ANL/NDM-5 Delayed Neutron Data - Review and Evaluation by Samson A. Cox, Apr11 1974.

ANL/NDM-6 Evaluated Neutronic Cross Section File for Niobium by R. Howerton, Lawrence Livermore Laboratory and A. SmIth, P. Guenther and J. Whalen, Argonne Nationa1 Laboratory, May 1974.

ANL/NDM-7 Neutron Total and Scattering Cross Sections of Some Even Isotopes of Molybdenum and the Optical Model by A. B. Sm1th, P. T. Guenther and J. F. Whalen, June 1974.

ANL/NDM-8 Fast Neutron Capture and Activation Cross Sections of Niobium Isotopes by W. P. Poenitz, May 1974.

ANL/NDM-9 Method of Neutron Activation Cross Section Measurement for $E_{n}=$ 5.5-10 MeV Using the $D(d, n) \mathrm{He}^{-3}$ Reaction as a Neutron Source by D. L. Smith and J. W. Meadows, August 1974.

ANL/NDM-10 Cross Sections for (n,p) Reactions on ${ }^{27} \mathrm{Al}, 46,47,48 \mathrm{Ti},{ }^{54}, 56 \mathrm{Fe}$, ${ }^{58} \mathrm{Ni},{ }^{59} \mathrm{Co}$ and ${ }^{64} \mathrm{Zn}$ from Near Threshold to $10 \mathrm{MeV}$ by Donald L. Smith and James W. Meadows, January 1975.

ANL/NDM-11 Measured and Evaluated Fast Neutron Cross Sections of Elemental Nickel by P. Guenther, A. Smith, D. Smith and J. Whalen, Argonne National Laboratory and R. Howerton, Lawrence Livermore Laboratory, July 1975.

ANL/NDM-12 A Spectrometer for the Investigation of Gamma Radiation Produced by Neutron-Induced Reactions by Donald L. Smith, April 1975.

ANL/NDM-13 Response of Several Threshold Reactions in Reference Fission Neutron Fields by Donald L. Smith and James W. Meadows, June 1975.

ANL/NDM-14 Cross Sections for the ${ }^{66} \mathrm{Zn}(n, p)^{66} \mathrm{Cu},{ }^{113} \operatorname{In}\left(n, n^{\prime}\right)^{113 m}$ In and il ${ }^{2} \mathrm{n}\left(n, n^{\prime}\right)^{115} \mathrm{~m}$ In Reactions from Near Threshold to $10 \mathrm{MeV}$ by Donald L. Smith and James W. Meadows, July 1975. 
ANL/NDM-15 Radiative Capture of Fast Neutrons in ${ }^{165} \mathrm{Ho}$ and ${ }^{181} \mathrm{Ta}$ by $W . P$. Poenltz, June 1975.

ANL/NDM-16 Fast Neutron Excitation of the Ground-State Rotational Band of ${ }^{238_{\mathrm{U}}}$ by $\mathrm{P}$. Guenther, D. Have1 and A. Suith, September 1975.

ANL/NDM-17 Sample-Size Effects In Fast-Neutron Gama-Ray Production Measurements: Solid-Cylinder Samples by Donald L. Suith, September 1975.

ANL/NDM-18 The Delayed Neutron Yield of ${ }^{238} \mathrm{U}$ and ${ }^{241} \mathrm{Pu}$ by J. W. Meadows January 1976.

ANL/NDM-19 A Remark on the Prompt-Fission-Neutron Spectrum of ${ }^{252} \mathrm{Cf}$ by P. Guenther, D. Havel, R. S joblom and A. Smith, March 1976.

ANL/NDM-20 Fast-Neutron-Gamma-Ray Production from Elementa1 Iron: $E_{n} \lesssim$ $2 \mathrm{MeV}$ by Donald L. Smith, May 1976.

ANL/NDM-21 Note on the Experimental Determination of the Relative FastNeutron Sensitivity of a Hydrogenous Scintillator by $A$. Saith, P. Guenther and R. Sjoblom, June 1976.

ANL/NDM-22 Note on Neutron Scattering and the Optical Model Near $A=208$ by P. Guenther, D. Havel and A. Smith, September 1976.

ANL/NDM-23 Remarks Concerning the Accurate Measurement of Differential Cross Sections for Threshold Reactions Used in Fast-Neutron Dosimetry for Fission Reactors by Donald L. Smith, December 1976.

ANL/NDM-24 Fast Neutron Cross Sections of Vanadium and an Evaluated Neutronic File by P. Guenther, D. Havel, R. Howerton, F. Mann, D. Smith, A. Smith and J. Whalen, May 1977.

ANL/NDM-25 Determination of the Energy Scale for Neutron Cross Section Measurements Employing a Monoenergetic Accelerator by J.W. Meadows, January 1977.

ANL/NDM-26 Evaluation of the IN-115(N,N')IN-115M Reaction for the ENDF/B-V Dosimetry File by Donald L. Smith, December 1976.

ANL/NDM-27 Evaluated ( $n, p)$ Cross Sections of ${ }^{45} \mathrm{TI},{ }^{47} \mathrm{Ti}$ and ${ }^{48} \mathrm{TI}$ by $\mathrm{C}$. PhIlis and 0 . Bersilion, Bruyeres-le-Chatel, France and $D$. Salth and $A$. Smith, Argonne National Laboratory, January 1977.

ANL/NDM-28 Titanium-II: An Evaluated Nuclear Data File by C. Philis, Centre d'Etudes de Bruyéres-le-Châtel, R. Howerton, Lawrence Livernore Laboratory and A. B. Smith, Argonne National Laboratory, June 1977.

ANL/NDM-29 Note on the $250 \mathrm{keV}$ Resonance in the Total Neutron Cross Section of ${ }^{6} \mathrm{LI}$ by A. B. Smith, P. Guenther, D. Havel and J. F. Whalen, June 1977. 
ANL/NDM-30 Analysis of the Sensitivity of Spectrum-Average Cross Sections to Individual Characteristics of Differential Excitation Functions by Donald L. Smith, March 1977.

ANL/NDM-31 Titanium-I: Fast Neutron Cross Section Measurements by P. Guenther, D. Have1, A. Sm1th and J. Whalen, May 1977.

ANL/NDM-32 Evaluated Fast Neutron Cross Section of Uranium-238 by W. Poenitz, E. Pennington, and A. B. Smith, Argonne National Laboratory and $R$. Howerton, Lawrence LIvermore Laboratory, October 1977.

ANL/NDM-33 Comments on the Energy-Averaged Total Neutron Cross Sections of Structural Materials by A. B. Smith and J. F. Whalen, June 1977.

ANL/NDM-34 Graph1cal Representation of Neutron D1fferential Cross Section Data for Reactor Dosimetry Applications by Donald L. Smith, June 1977.

ANL/NDM-35 Evaluated Nuclear Data File of Th-232 by J. Meadows, W. Poenftz, A. Smlth, D. Smith and J. Whalen, Argonne National Laboratory and $R$. Howerton, Lawrence Livermore Laboratory, February 1978.

ANL/NDM-36 Absolute Measurements of the ${ }^{233} \mathrm{U}(\mathrm{n}, \mathrm{f})$ Cross Section Between 0.13 and $8.0 \mathrm{MeV}$ by W. P. Poenttz, Apr11 1978.

ANL/NDM-37 Neutron Inelastic Scattering Studies for Lead-204 by D. L. Sm1th and J. W. Meadows, December 1977.

ANL/NDM-38 The Alpha and Spontaneous Fission Half-Lives of ${ }^{242} \mathrm{Pu}$ by J.W. Meadows, December 1977.

ANL/NDM-39 The Fission Cross Section of ${ }^{239} \mathrm{Pu}$ Relative to ${ }^{235} \mathrm{U}$ from 0.1 to $10 \mathrm{MeV}$ by J. W. Meadows, March 1978.

ANL/NDM-40 Statistical Theory of Neutron Nuclear Reactions by P. A. Moldauer, February 1978.

ANL/NDM-41 Energy-Averaged Neutron Cross Sections of Fast-Reactor Structural Materials by A. Smith, R. Mcknight and D. Smith, February 1978.

ANL/NDM-42 Fast Neutron Radiative Capture Cross Section of ${ }^{232}$ Th by W. P. Poenitz and D. L. Smith, March 1978.

ANL/NDM-43 Neutron Scattering from ${ }^{12} \mathrm{C}$ in the Few-MeV Region by A. Snith, R. Holt and J. Whalen, September 1978.

ANL/NDM-44 The Interaction of Fast Neutrons with $60 \mathrm{N1}$ by A. Smith, P. Guenther, D. Smith and J. Whalen, January 1979.

ANL/NDM-45 Evaluation of $235 \mathrm{U}(\mathrm{n}, \mathrm{f})$ between $100 \mathrm{KeV}$ and $20 \mathrm{MeV}$ by W. P. Poenitz, July 1979. 
ANL/NDM-46 Fast-Neutron Total and Scattering Cross Sections of ${ }^{107}{ }^{A g}$ in the MeV Region by A. Smith, P. Guenther, G. Winkler and J. Whalen, January 1979.

ANL/NDM-47 Scattering of MeV Neutrons from Elemental Iron by A. Silth and P. Guenther, March 1979.

ANL/NDM-48 235U Fission Mass and Counting Comparison and Standardization by W. P. Poenttz, J. W. Meadows and R. J. Arman1, May 1979.

ANL/NDM-49 Some Comments on Resolution and the Analysis and Interpretation of Experimental Results from Differential Neutron Measurements by Donald L. Smith, November 1979.

ANL/NDM-50 Prompt-Fission-Neutron Spectra of $233_{\mathrm{U}}, 235 \mathrm{U}, 229 \mathrm{Pu}$ and $240 \mathrm{Pu}$ Relative to that of ${ }^{252} \mathrm{Cf}$ by A. Smith, P. Guenther, G. Winkler and R. McKnight, September 1979.

ANL/NDM-51 Measured and Evaluated Neutron Cross Sections of Elemental Bismuth by A. Smith, P. Guenther, D. Smith and J. Whalen, Apr11 1980.

ANL/NDM-52 Neutron Total and Scattering Cross Sections of "Li in the Few $\mathrm{MeV}$ Region by P. Guenther, A. Smith and J. Whalen, February 1980.

ANL/NDM-53 Neutron Source Investigations in Support of the Cross Section at the Argonne Fast-Neutron Generator by James W. Meadows and Donald L. Smith, May 1980.

ANL/NDM-54 The Nonelastic-Scattering Cross Sections of Elemental Nickel by A. B. Smith, P. T. Guenther and J. F. Whalen, June 1980 .

ANL/NDM-55 Thermal Neutron Calibration of a Tritium Extraction Facility using the ${ }^{6} \mathrm{LI}(\mathrm{n}, \mathrm{t})^{4} \mathrm{He} /{ }^{197} \mathrm{Au}(\mathrm{n}, \gamma){ }^{198} \mathrm{Au}$ Cross Section Ratio for Standardization by M. M. Bretscher and D. L. Smith, August 1980.

ANL/NDM-56 Fast-Neutron Interactions with $182 \mathrm{~W}, 184 \mathrm{~W}$ and $186 \mathrm{~W}$ by P. T. Guenther, A. B. Sm1th and J. F. Whalen, December 1980.

ANL/NDM-57 The Total, Elastic- and Inelastic-Scattering Fast-Neutron Cross Sections of Natural Chromfum, Peter T. Guenther, Alan B. Swith and James $F$. Whalen, January 1981.

ANL/NDM-58 Review of Measurement Techniques for the Neutron Capture Process by W. P. Poentiz, August 1981 . 
TABLE OF CONTENTS

Page

LIST OF FIGURES................................. vil

LIST OF TABLES.................................. vili

ABSTRACT..........................................

I. INTRODUCTION $\ldots \ldots \ldots \ldots \ldots \ldots \ldots \ldots \ldots \ldots \ldots \ldots \ldots \ldots \ldots \ldots \ldots \ldots \ldots$

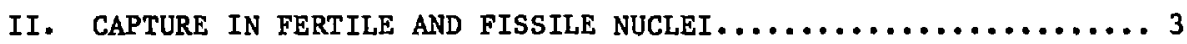

1. Fertile Nuclei............................. 4

2. Fissile Nuclei.............................. 5

III. Capture IN STRUCTURAL, COOLANT AND SHIELDING MATERIALs...... 6

IV. CAPTURE IN FISSION PRODUCT NUCLEI.................... 10

1. Thermal Reactors........................... 10

2. Fast Reactors.............................. 12

v. THE PRODUCTION OF HIGHER ACTINIDES................. 15 


\section{LIST OF FIGURES}

No.

Title

1. Experimental Results for the Thermal Neutron Capture Cross Section of $238 \mathrm{U}$. The ENDF/B-V Value is also shown...................

2. Comparison of Experimental Data with a Theoretically Calculated Cross Section of $238_{U(n, y) \ldots \ldots \ldots \ldots \ldots \ldots \ldots \ldots \ldots \ldots \ldots \ldots \ldots \ldots \ldots \ldots \ldots \ldots \ldots \ldots \ldots \ldots} \ldots \ldots \ldots$

3. Fluctuations of the ${ }^{238} \mathrm{U}$ Neutron Capture Cross Section in the 10 $90 \mathrm{keV}$ Region. The Data by DeSaussure et al. ${ }^{30}$ Averaged with Various Resolutions Relative to a Smoothly Averaged Cross Section are Shown.............................................

4. Comparison of Recent Experimental Data with a Theoretically Ca1culated Cross Section of ${ }^{232} \mathrm{Th}(\mathrm{n}, \gamma) \ldots \ldots \ldots \ldots \ldots \ldots \ldots \ldots \ldots \ldots \ldots \ldots$

5. The Neutron Capture Cross Sections of ${ }^{56} \mathrm{Fe},{ }^{58} \mathrm{Ni},{ }^{60} \mathrm{Ni}$ ane ${ }^{61} \mathrm{Ni}$ Narrow p-Wave Resonances with Large Peak Cross Sections and Wide S-Wave Resonances are Evident. The Odd-Mass Nuclei $6 \mathfrak{l}_{\mathrm{N}}$ has a Substantially Larger Cross Section than the Even-Mass Isotopes.........................................

6. The Neutron Capture Cross Sections of the Fission Product Poisons

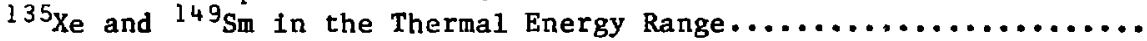

7. Experimental Data, a Theoretical Calculation, and two Evaluations of the Neutron Capture Cross Section of ${ }^{109} \mathrm{Ag}$. Discrepancles Exceeding a Factor of Two are Obvious in Both, Experimental Results and Evaluations...............................

8. More Recent Experimental Results for the Fast Neutron Capture Cross Section of $103_{R h}$. The Data are in a \pm 15 Percent Range, thus Falling Short of the \pm 7 Percent Required for Technological Applications. Cross Section Values, Multiplied by the Squareroot

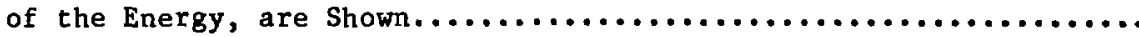

9. A Schematic of the Build-up of the Higher Actinides. Neutron Capture is Indicated by Horizontal Double-Solid Arrows............

10. The Neutron Capture Cross Section of $240 \mathrm{Pu}$. Experimental Data are Shown Along with a Theoretical Calculation (Solld Line) and the Evaluation of ENDF/B-V (Dotted Line) 
No.

$\underline{\text { Title }}$

$\underline{\text { Page }}$

I. Fractions of Capture Events in an LMFBR at Start-up...........

II. Breeding Ratio Components of a Metal Fueled Pu/U LMFBR......... 3

III. Thermal Neutron Capture Cross Sections of Fissile Nuclei.......6 6

IV. Experimental $\Gamma_{\gamma}$ - Values for two Resonances of ${ }^{56} \mathrm{Fe} \ldots \ldots \ldots \ldots \ldots$

V. Percent Changes of One-Group Cross Sections Between ENDF/B-V

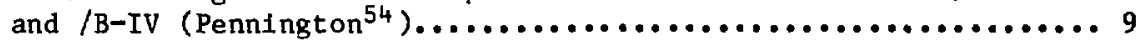

VI. Accumulated Neutron Capture Events in Individual Fission Products Relative to Total Captures in Fission Products after $4000 \mathrm{~h}$ and $26400 \mathrm{~h}$ of Reactor Operation

VII. The Twenty-five Most Important Fission Product Absorbers in Fast Reactor Cores (Schenter and England ${ }^{55}$ )............... 13

VIII. Comparison Between Different Calculated Fission Product Capture Cross Sections (in mbarn) at $2 \mathrm{MeV}$ (Iijima et al. ${ }^{60}$ )........... 14

IX. Comparison of the Yearly Production of Transactinides in LWR's

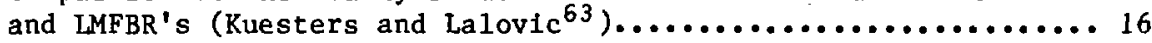

X. Effect of the Transactinides on Fast Breeder Parameters (Barre and Bouchard ${ }^{64}$ ). 


\title{
Review of the Neutron Capture Process in Fission Reactors*
}

by

\author{
W. P. Poenitz \\ Applied Physics Division \\ Argonne National Laboratory \\ 9700 South Cass Avenue \\ Argonne, Illinots 60439 U.S.A.
}

\begin{abstract}
The importance of the neutron capture process and the status of the more important cross section data are reviewed. The capture in fertile and fissile nuclei is considered. For thermal reactors the thermal to epithermal capture ratlo for $238 \mathrm{U}$ and $232 \mathrm{Th}$ renains a problem though some improvements were made with more recent measurements. The capture cross section of ${ }^{238} \mathrm{U}$ in the fast energy range remains quite uncertain and a long standing discrepancy for the calculated versus experimental central reaction rate ratio C28/F49 persists. Capture in structural materials, fission product nuclei and the higher actinides is also considered.
\end{abstract}

*This work supported by the U.S. Department of Energy. 


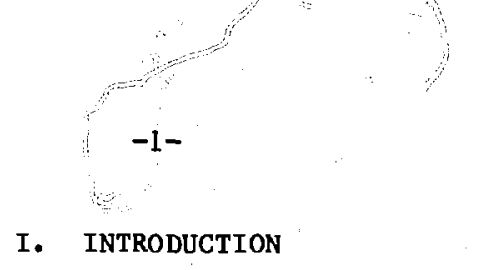

The neutron radiative capture process plays an important role in many aspects of nuclear power reactors and the assoctated fuel cycles. Presently operated thermal reactors burn fissile nuclei $\left({ }^{235} \mathrm{U},{ }^{239} \mathrm{Pu}\right.$, and $\left.{ }^{233} \mathrm{~V}\right)$ with the main objective of electrical power generation. However, the najor thrust of the current reactor-research programs is oriented toward fast-breeder reactors which will not only produce electrical power but also convert, by neutron capture, abundant ${ }^{23} 8 \mathrm{U}$ to f1ssile fuel ${ }^{239} \mathrm{Pu}$ (or $232 \mathrm{Th}$ to $233 \mathrm{U}$ ) which can in turn bu used for further breeding or as fuel for thermal reactors in place of scarce ${ }^{235} \mathrm{U}$. The power production and the maintenance of the fission chain reaction in a reactor is based on the fission process, e.g. for ${ }^{235} \mathrm{U}$ :

$$
235 \mathrm{U}+\mathrm{n}+\mathrm{F}_{1}+\mathrm{F}_{2}+\nu \cdot \mathrm{n}+\sim 180 \mathrm{MeV}
$$

where $F_{1}$ and $F_{2}$ are two fission products and $\nu$ is the average number of neutrons emitted per fission event. In a controlled nuclear chain reaction one of these neutrons must be avallable to inftiate a new fission event. The remaining neutrons will be lost due to radlative capture in the fissile material, the fission product nuclei, the structural materials, and the coolant. They may also be lost due to absorption in the control rods or due to leakage from he reactor core and subsequent capture in the reactor shielding materlals. In breeder reactors enough of the excess neutrons are captured in the fertile materials, e.g. ${ }^{238} \mathrm{U}$ :

$$
238 \mathrm{U}+\mathrm{n}+239 \mathrm{U} \stackrel{\mathrm{Tl} / 2=23.6 \mathrm{~m}}{\longrightarrow} 239 \mathrm{~Np} \stackrel{2.355 \mathrm{~d}}{\longrightarrow} 239 \mathrm{Pu},
$$

to produce more new fissile nuclel than are lost due to fission events. The above rough sketch clearly indicates the importance of the knowledge of capture cross sections for the calculation of the neutron economy in a reactor and for the evaluation of nuclear fuel cycles.

The fraction of neutrons lost due to radiative capture in fissile nuclei is usually expressed with the capture-to-fission ratio, $\alpha=\sigma_{n, \gamma} / \sigma_{n}, f$, which affects the number of neutrons produced per neutron absorbed, $n=v \cdot \sigma_{n, f} /$ $\left(\sigma_{n, f}+\sigma_{n, \gamma}\right)=\nu /(1+\alpha)$. For breeder reactors an important quantity is the "breeding ratio" which is the number of new fissile nuclei produced per fission event and given by

$$
\mathrm{BR}=\eta-1-A-L+\left(\nu^{\prime}-1\right) \mathrm{F}
$$

where $A$ is the loss due to parasitic absorptions (mainly capture) in fission products, structural materials, coolant, and other materials, L is the leakage, and $F$ are the fissions in fertile materials; thus a bonus ( $v$ ' is the average number of fission neutrons in the fertile materials). The leakage term, $L$ is dependent on the size of the reactor and usually about a factor of 3-5 saller 
than the absorption loss, A. The breeding ratio determines the economically important "doubling time", that is, the time needed to double the usable fissile fuel via the "breeding gain" (BR-1).

Table I gives the fractions of capture events in various reactor materials for a typical $1000 \mathrm{MW}$ sodium cooled fast breeder reactor (LMFBR) at start up time (LeSage et al. ${ }^{1}$ ).

Table I. Fractions of Capture Events in an IMFBR at Start-up:

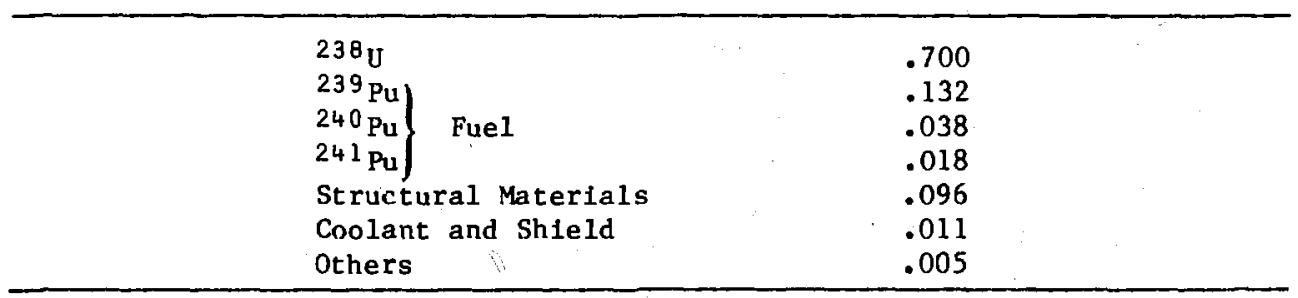

The reactor is assumed to be inftially fueled by plutonium obtalned from reprocessing of spent thermal reactor fuel elements. It is obvious that the capture in the fertile material, in this case ${ }^{238} \mathrm{U}$, is the most important. As the burnup of the fuel proceeds fission products become an appreciable polson. Capture in the fission products decreases the reactivity of the reactor with increasing burn-up. This must be provided for with excess reactivity in the design. Neutron capture in fissile nuclei leads to a build-up of heavier nuclei, some with longer half lives which usually are $\alpha$-emitters. Though neutrons are lost due to capture in these transactinides, they hav only a minor effect on the neutronics of a reactor because some are fissile nucle1 which compensate for the neutron capture losses with gains via fission events. Although the production of higher actinides does not influence the neutronics of the reactor appreciably, they play an important aspect in other parts of the fuel-cycle, such as afterheat, waste-management and spent-fuel handling. The contributions of the different processes to the neutron economy can be seen in Table II which shows the number of neutrons contributing to the breeding gain averaged over the fuel cycle (Chang and Till ${ }^{2}$ ). 
Table II. Breeding Ratio Components of a Metal Fueled Pu/U LMFBR

$\begin{array}{ll}\text { Neutron Gains } & \\ \eta \text { of Fissile Isotope } & 2.450 \\ \text { Fertile Fission Bonus } & 0.509 \\ & \\ \text { Neutron Losses } & \\ \text { Capture in Structural Materials } & 0.127 \\ \text { Capture in Fission Products } & 0.058 \\ \text { Capture in Coolant } & 0.008 \\ \text { Other Absorption Losses } & 0.025 \\ \text { Leakage Loss } & 0.082 \\ \text { 24l Pu Decay Loss } & 0.032 \\ & \\ \text { Net Neutrons for Breeding } & 1.627 \\ \text { (Capture in 238 U) } & \end{array}$

An increase of the temperature in a reactor causes the Doppler-broadening of the resonances to increase and result in a reactivity change due to a decrease of the resonance-self-shielding effect. Capture in ${ }^{238} \mathrm{U}$ is the major source for the Doppler-effect and important for the control and safe operation of reactors.

Another aspect of the capture process is the $\gamma$-radiation against which the environment must be shielded. The appropriate calculation of the shielding requirements demands not only a knowledge of the frequency of the capture events but a knowledge of the assoclated $\gamma$-ray spectrum as well.

\section{CAPTURE IN FERTILE AND FISSILE NUCLEI}

The dominance of neutron capture in the major fertile ( ${ }^{238} \mathrm{U}$, and $\left.{ }^{232} \mathrm{Th}\right)$ and fissile $\left({ }^{233} \mathrm{U},{ }^{235} \mathrm{U}\right.$, and $\left.{ }^{239} \mathrm{Pu}\right)$ nuclei compared with capture in other materials follows from the relative abundance of these materials in a reactor and the size of their cross sections. The capture cross sections at thermal energies are substantially larger for fissile nuclei $(\gg 100 \mathrm{~b})$ than for the fertile nuclei (2.7 and $7.4 \mathrm{~b}$ for $238 \mathrm{U}$ and $232 \mathrm{Th}$, respectively). Thus, a larger amount of neutrons is lost by capture in fissile nuclei in thermal than in fast reactors and $\alpha$ and $\eta$ play a more significant role. The neutron spectra in fast reactors peak in the $\sim 10-\sim 100 \mathrm{keV}$ range where the average capture cross sections of fertile and fissile nuclei are similar in size. As a consequence of the higher abundance of the fertile materials in fast reactors the neutron capture in these materials is of overwhelming importance as can be seen from Tables $\mathrm{I}$ and II.

The importance of the fertile and fissile nuclei with respect to neutron capture would lead us to expect that their cross sections are very well known. However, a number of problems have persisted for many years for which solutions are not yet in sight, though some improvements have been made. These problems may not be caused by a lack of knowledge of the cross section data 
alone. Shortcomings of some models and approximations used to represent reactors or test facilities may contribute to these problems as well.

1. Fertile Nuclei ${ }^{238} \mathrm{U}$ Capture

Measured values of the thermal neutron capture cross section of ${ }^{238} \mathrm{U}$ obtained with different experimental techniques are generally in good agreement. The available data are shown in Fig. 1. The $2200 \mathrm{~m} / \mathrm{sec}$ value of $2.70 \mathrm{~b}$ from both, ENDF/B-IV and ENDF/B-V, is somewhat lower than the weighted average of the experimental data (2.711b) but agrees better with a value of $2.701 \mathrm{~b}$ derived from the resonance parameters (Tomlinson et al.13). The resonance region presents a substantial problem. Resonance capture in thermal reactors accounts for about half of all ${ }^{238} \mathrm{U}$ capture events and is strongly resonance self-shielded due to its concentration in the fuel elements. Calculations of the ratio of resonance capture vs. thermal capture with ENDF/B-IV data exceed the measured values by 3.6-5.8\% (McCrosson and Hardy ${ }^{14}$ ). Recent experiments on the lower s-wave resonances by olson et al. 15, Lion and Chrien ${ }^{16}$, Poortmans et al. 17 , and Block et al. ${ }^{18}$, brought a reduction of $\Gamma_{\gamma}$ by $\sim 15 \%$ which was incorporated in $E N D F / B-V$ and helped to improve the epithermal-to-thermal neutron capture ratio.

Stringent requirements are needed in the fast neutron energy range which is of Interest for LMFBR's. Uncertainties of the ${ }^{238} \mathrm{U}$ capture cross section as low as $1.5-3 \%$ are requested for the lower keV range and 3-10\% in the higher $\mathrm{keV}$ and $\mathrm{MeV}$ range (Weisbin et al.19, Usachev and Bobkov ${ }^{20}$ ). The uncertainties achieved with more recent measurements of the ${ }^{238} \mathrm{U}$ neutron capture cross section are at best $\pm 5 \%$ below $500 \mathrm{keV}$ and $\pm 10 \%$ above (See review by Poenftz ${ }^{21}$ ). Major problems which exist in the high energy range are the calculated vs. experimental (CE) central reaction rate ratio discrepancy for ${ }^{238} \mathrm{U}(\mathrm{n}, \gamma) /{ }^{239} \mathrm{Pu}(\mathrm{n}, \mathrm{f})$ and the small sample central reactivity worth discrepancy for ${ }^{238} \mathrm{U}$. The central reaction rate ratio in reactor test factlfties is usually calculated 3-9\% higher than the experimentally determined value (LeSage and McKnight ${ }^{22}$ ). The CE-discrepancy for the small sample central reactivity worth is in the order of $\sim 20 \%$ and adjustments of the capture cross section in the order of $12 \%$ would be required to resolve this problem $\left(\mathrm{Bohn}^{23}\right)$.

Figure 2 show the more recent data measured for the ${ }^{238} \mathrm{U}(\mathrm{n}, \gamma)$ cross section in the fast neutron energy range. The cross section values are multiplied by the square root of the energy which allows these data to be displayed on a linear scale. Also shown in F1g. 2 is a cross section curve calculated in terms of the statistical and optical models and normalized with experimental values of $\Gamma_{Y} / D$ obtained from resolved resonance parameters. Other parameters were selected to best represent the experimental data. The agreement of the experimental data with the calculated cross section curve appears to be generally within a $\pm 5 \%$ range which is also shown in Fig. 2 . The capture cross section of ${ }^{238} \mathrm{U}$ fluctuates around the average in the unresolved resonance range. This can be seen in $\mathrm{FIg}$. 3 where the capture cross section relative to its average is shown for different resolutions. These fluctuations cause some of the lowresolution data shown in $\mathrm{Fig}$. 2 to scatter around the calculated curve, however, they have a negligible impact on reactor performance. 


\section{Th Capture}

Although 232 Th has been studied as a fertile material in experimental. facilities and is in use in the Canadian reactor program (CANDU's), it was only more recently that interest in thorium increased substantially: Th not only presents an energy reserve which about equals that of ${ }^{238} \mathrm{U}$ but also provides some options for alternative fuel cycles. Recent interest in ${ }^{232} \mathrm{Th}$ has led to reviews which have shown the capture cross section data for this nucleus to be more sparce and uncertain than for ${ }^{238}{ }_{\mathrm{UJ}}$.

The thermal capture cross section appears reasonably well established. Two more recent measurements $\left(7.33 \pm .17 \mathrm{~b}\right.$, Poenitz and Smith ${ }^{31}, 7.41 \pm .08 \mathrm{~b}$, Chrien et al. ${ }^{32}$ ) agree well with the ENDF/B-IV value of $7.40 \mathrm{~b}$.

Calculations of the epithermal vs. thermal capture ratio using ENDE/B-iv resulted in substantially lower values than experimentally observed (U110 et a1.33). New measurements of the ${ }^{232} \mathrm{Th}$ resonances below $100 \mathrm{eV}$ by Chrien et $a 1.32$ resulted in resonance parameters $\left(E_{O}, \Gamma_{n}, \Gamma_{\gamma}\right)$ in good agreement with values recommended by Derrien ${ }^{34}$. However, the measured capture cross section was found to be substantially larger than ENDF/B-IV (up to a factor of 2) below the lowest energy resonance. Partial incorporation of these new measurements in ENDF/B-V should improve the CE-discrepancy for the epithermal-to-thermal capture ratio.

Recent measurements of the capture cross section in the unresolved and higher energy range (Macklin and Halperin ${ }^{35}$, Lindner et al.27, Poenitz and Smith ${ }^{31}$, Chrien et al. ${ }^{32}$, and Yamamuro et a1. ${ }^{36}$ ) resulted in data about $30 \%$ lower than older measurements. After revision of the data by Macklin and Halperin ${ }^{35}$ agreement between the newer data is within $\sim \pm 5 \%$. The data are shown in Fig. 4.

\section{Fissile Nucle1 $239 \mathrm{Pu}, 235 \mathrm{U}$ and ${ }^{233} \mathrm{U}$}

The neutron capture in fissile materials in thermal reactors appears to be sufficiently well known for neutronic calculations. Problems which exist in calculating parameters of test facilities seem to be related to other quantities, such as the fission spectra and resonance capture in the fertile materials. The thermal capture cross sections of the fissile nuclei ${ }^{233} \mathrm{U},{ }^{235} \mathrm{U}$ and ${ }^{239} \mathrm{Pu}$ were recently obtained in consistency fits of various experimental data $\left(\sigma_{\text {tot }}, \sigma_{n, f}, \eta, \sigma_{n, n}, \sigma_{\text {abs }}, \alpha, \nu\right.$, and $\nu$ of $252 \mathrm{Cf}$ ) which resulted in uncertainties of $\sim 1-11 / 2 \%$ for the capture cross sections of ${ }^{235} \mathrm{U}$ and ${ }^{239} \mathrm{Pu}$ and $\sim 5 \%$ for ${ }^{233} \mathrm{U}$ (Holden and Stehn ${ }^{37}$ ). The values are given in Table III and compared with ENDF/B-IV and $-V$ values. 
Table III. Thermal Neutron Capture Cross Sections of Fissile Nuclei (in barn)

\begin{tabular}{|c|c|c|c|}
\hline & ENDF/B-IV & Consistency F1t & ENDF/B-V \\
\hline $\begin{array}{l}233 \mathrm{U} \\
235 \mathrm{U} \\
239 \mathrm{Pu}\end{array}$ & $\begin{array}{r}46.20 \\
97.22 \\
269.71\end{array}$ & $\begin{array}{r}46.40 \pm 2.36 \\
98.85 \pm 1.13 \\
269.84 \pm 2.95\end{array}$ & $\begin{array}{r}45.76 \\
98.38 \\
270.20\end{array}$ \\
\hline
\end{tabular}

Agreement is rather good between the differently evaluated values. The rather large uncertainty for ${ }^{233} \mathrm{U}$ is not detrimental for neutronic calculations as the sensitivities of keff to cross section changes are low (U11o et $\left.a 1 .{ }^{33}\right)$.

The capture in fissile nuclei is also satisfactorily known for fast reactor applications. The capture cross sections are derived from captureto-fission ratio $(\alpha)$ measurements for which reasonable agreement has been achieved in various experiments. $\alpha$ of ${ }^{239} \mathrm{Pu}$ stirred considerable interest when measurements by Schomberg et al. ${ }^{38}$ in 1967 resulted in differences of up to a factor of 2 from the contemporary accepted evaluated data. Subsequent measurements by Schomberg and Sowerby ${ }^{39}$, Gwin et al.40, and Ryabov et al.41 confirmed the deficiency of $\alpha$ in the lower $\mathrm{keV}$ range though not to the extent originally suggested. Values differing by up to $15 \%$ from ENDF/B-V were recently found for the capture cross section of ${ }^{235} \mathrm{U}$ between 1 and $160 \mathrm{keV} .42$ Though this possible discrepancy has little effect on LMFBR-designs, which are expected to be Pu-fueled, it would affect calculations of U-fueled test-facilities or first-generation LMFBR's which might be ${ }^{235} \mathrm{U}$-fueled.

\section{CAPTURE IN STRUCTURAL, COOLANT AND SHIELDING MATERIALS}

The thermal capture cross sections of structural materials are usually very small compared with cross sections for other materials involved in a reactor. This results in a reduced importance of these materials for the neutron economy in thermal reactors than is the case for fast reactors where cross section differences are less pronounced. Therefore, we will consider the capture in structural materials only in the context of fast reactors. The importance of the structural and coolant materials for fast reactor designs can be expected from the typical volume - percent distributions of $\sim 60 \%$ for fuel (fissile and fertile), $\sim 20 \%$ for structural materials, and $\sim 20 \%$ for coolant. Sodium is considered in LMFBR designs as a coolant and also as a shield surrounding the core and reflector. Structural material appears in the form of fuel-cladding and supportive structures and consists mainly of stainless steel. Though the composition of stainless steel might vary widely, typical values which are used in design concepts are

$$
\begin{array}{ll}
\sim 60-70 \% \text { Fe } \\
\sim 18-20 \% \text { Cr } \\
\sim 10-13 \% \text { Ni } \\
\sim 2 \% & \text { Mo, Mn. }
\end{array}
$$


The capture cross sections of these elements averaged over a fast reactor spectrum differ such that the relative importance of $\mathrm{Cr}$ and $\mathrm{N} 1$ are inverted, the importance of $\mathrm{Fe}$ is decreased and the role for Mo and $\mathrm{Mn}$ is substantially increased.

Capture in structural materials is more important than capture in the fission products by a factor of 2-3 (see Table II). It influences the critical enrichment and the breeding gain. The commonly accepted goals for the design accuracy in $k_{\text {ef }}$ and the $B R$ of $0.5-1.0 \%$ and $2 \%$, respectively, leads to requests for capture cross section uncertainties of 5-10\% for Fe, $\mathrm{Cr}$, and $\mathrm{N} 1$ anc $10 \%$ for Mo and Mn.

The isotopic compositions of the elemental $\mathrm{Fe}$ and $\mathrm{Cr}$ are dominated by one major isotope each $\left({ }^{56} \mathrm{Fe}, 91.7 \%\right.$, and ${ }^{52} \mathrm{Cr}, 83.8 \%$ ) whereas for $\mathrm{Ni}$ two isotopes contribute larger amounts $\left({ }^{58} \mathrm{Ni}, 67.8 \%\right.$, and $\left.{ }^{60} \mathrm{Ni}, 26.2 \%\right)$. All of thiese isotopes are in a mass range where the cross sections in the main region of the fast reactor spectrum show distinct resonances. S-wave resonances in this range are large and broad and therefore strongly selfshielded, whereas p-wave resonances are narrow and small, and less selfshielded. Figure 5 shows as an example the capture cross sections of ${ }^{56} \mathrm{Fe}$, ${ }^{58} \mathrm{Ni},{ }^{60} \mathrm{Nf}$ and ${ }^{61} \mathrm{Ni}$. The dominance of one or two isotopes in the isotopic composition of $\mathrm{Fe}, \mathrm{Cr}$, or $\mathrm{Ni}$ does not imply that the minor isotopes play a correspondingly unimportant role. The level spacings vary greatly among the various isotopes (up to a factor of 10) and the differences of tine resonance parameters increases the importance of some and decreases it for others. An example is ${ }^{53} \mathrm{Cr}$ which occurs with only $9.5 \%$ in the isotopic composition of chromium but has an average capture section which is about a factor of 100 larger than that of the primary 1sotope ${ }^{52} \mathrm{Cr}$, and thus dominates the capture in elemental chromium.

The resonance nature of the cross sections of the structural materials results in their significant importance for the Doppler-effect in fast reactors. They contribute about as much as the fissile nuclei, but less than the fertile nuclei. - The narrow p-wave resonances are strongly Doppler-broadened whereas the Doppler-broadening contributes little to the wide S-wave resonances. The major part $(\sim 50-80 \%)$ of the Doppler-effect caused by structural materials in fast reactors is due to the $1.5 \mathrm{eV} \mathrm{p}$-wave resonance of ${ }^{56} \mathrm{Fe}$ and the uncertainties of its resonance parameters contribute about $90 \%$ to the uncertainty in calculating the Doppler-effect of structural materials (Takano and Ishiguro ${ }^{43}$ ).

Measurements of the capture cross sections of structural materials encounter two major difficulties. The first problem is the spectrum of the $\gamma$-rays emitted in the capture process which is dominated by strong transitions to the ground state or low-lying excited states. This results in an appreciable spectral sensitivity of total-energy detectors (large-liquid scintillators) which is visible in changes of the measured pulse-height distribution (see Fig. 13, ANL/NDM-58). Some effect can also be expected from energy-proportional detectors because the transitions from the low-lying states fall into a range where the detector efficiency is not proportional to the $\gamma$-ray energy.

The second problem results from the much larger scattering than capture cross sections with $\Gamma_{n} / \Gamma_{Y}$ typically in a range of $10^{3}$ to $10^{4}$. This results in a large fraction of the interacting neutrons being scattered and subsequently causing secondary neutron capture events within the samples. 
Required corrections for this effect are in the order of a factor of 2. The scattered neutrons cause an additional problem due to the neutron sensitivity of the capture $\gamma$-ray detectors. Several observations by Moxon et $a 1.44$ may be explained in light of this problem: a) $r_{\gamma}$ values for $p$-wave resonances (which have much smaller $\Gamma_{n} / \Gamma_{\gamma}$ values) were reported to be smaller by factors of 2-3 than for s-wave resonances, b) capture cross section measurenents with lead slowing-down spectrometers which have a very low neutron sensitivity usually yield lower values than those obtained with other techniques, and c) activation measurements of ten result in considerably lower cross section values than obtained with prompt detection techniques. The latter could also be due to the smaller samples used in activation measurements which reduces the capture probability for secondary neutrons.

Very few capture cross secton measurements on structural materials were carried out prior to 1965 . Some average cross section data were obtained with lead slowing-down spectrometers (Kapchigashev et al.45) at low energies and with large liquid scintillator detectors (Diven et $a 1.46$ ) at higher energies. The analysie of resonance parameters requires in addition to capture yield data, the krowledge of the total cross section. As a result of this data need, more recent experimental efforts were oriented toward the simultaneous provision of transmission and capture data. Such comprehensive total and capture cross section data sets were obtained for $50,52,53,54 \mathrm{Cr}$ and ${ }^{60} \mathrm{Ni}$ at Rensselaer Polytechnic Institute (Stieglitz et a1.47) and for $50,52,53 \mathrm{Cr}$, $54,57,58 \mathrm{Fe}$, and $61,62,64 \mathrm{N1}$ at Karlsruhe (Beer and Spencer, ${ }^{48}$ ). Many $\mathrm{p}$-wave resonances were found in the capture measurements but were missing in the transmission measurements due to a lack of resolution. The capture measurements yield only values of $g \Gamma_{n} \Gamma_{\gamma} / \Gamma$ and might be incorrect if the neutron capture data cannot be corrected for multiple scattering effects because of missing total cross section in ormation. Thus, the analysis of these data was in part incomplete.

Measurements with substantially improved resolution were carried out at Oak Ridge National Laboratory for the same and some additional isotopes (Allen et $a 1 \cdot{ }^{49}$ ). Such measurements were also made at the EURATOM 1aboratories at Geel for the isotopes $54,56,57 \mathrm{Fe}$, and $50,52,53 \mathrm{Cr}$ (Brusegan et al. ${ }^{50}$ ) and at Harwell for elemental iron, nickel and chromium (Gayther et a1.51) and various isotopes (James and Syme ${ }^{52}$ ).

Some of the problems in determining resonance parameters can be seen in Table IV which lists the experimental results for $\Gamma_{\gamma}$ of two important resonances of ${ }^{56} \mathrm{Fe}$. The $1.15 \mathrm{keV}$ resonance is a p-wave resonance and agreement for $\Gamma_{\gamma}$ is rather good. However, discrepancies are found even between newer measurements for the s-wave resonance at $27.7 \mathrm{keV}$. 
Table IV. Experimental $\Gamma_{Y}$ - Values for two Resonances of ${ }^{56} \mathrm{Fe}$

\begin{tabular}{|c|c|c|c|}
\hline $\mathrm{E}_{\mathrm{o}} / \mathrm{KeV}$ & Year & $\Gamma_{Y}$ & Reference 53 \\
\hline 1.15 & $\begin{array}{l}1964 \\
1965 \\
1969 \\
1977 \\
1977 \\
1979 \\
1979\end{array}$ & $\begin{array}{ll}0.60 & \pm 0.06 \\
0.56 & \\
0.57 & \pm 0.06 \\
0.785 & \pm 0.100 \\
0.60 & \pm 0.06 \\
0.615 & \pm 0.026 \\
0.610 \pm 0.060\end{array}$ & $\begin{array}{l}\text { Block } \\
\text { Moxon } \\
\text { Julien } \\
\text { Poortmans } \\
\text { Pereya } \\
\text { Gayther } \\
\text { Brusegan }\end{array}$ \\
\hline 27.7 & $\begin{array}{l}1968 \\
1970 \\
1977 \\
1977 \\
1977 \\
1979 \\
1979 \\
1979 \\
1979\end{array}$ & $\begin{array}{l}1.44 \pm 0.14 \\
1.40 \pm 0.02 \\
1.25 \pm 0.2 \\
1.60 \pm 0.2 \\
1.4 \pm 0.1 \\
0.75 \pm 0.20 \\
0.99 \pm 0.04 \\
0.85 \pm 0.05 \\
0.80 \pm 0.20\end{array}$ & $\begin{array}{l}\text { Hockenbury } \\
\text { Ernst } \\
\text { Froehnerb } \\
\text { Allen } \\
\text { Perey } \\
\text { Moxon } \\
\text { Wisshae } \\
\text { Gayther } \\
\text { Brusegan }\end{array}$ \\
\hline
\end{tabular}

analysis of various ORNL measurements.

beanalysis of the measurements by Ernst.

Although substantial improvements have been made for the capture cross sections of structural materials, uncertainties still remain exceeding the requested uncertainty levels of 5-10\%. Changes of the one-group cross section for several fast criticals ${ }^{54}$ (ZPR-6-6A, ZPR-6-7, and ZPR-9-31) between $E N D F / B-I V$ and $-V$ are indicative of the unsettled nature of these data (see Table V).

Table V. Percent Changes of One-Group Cross Sections Between ENDF/B-V and /B-IV (Pennington ${ }^{54}$ )

\begin{tabular}{cc}
\hline Material & $\bar{\sigma}_{\mathrm{n}, \gamma} \mathrm{V} / \bar{\sigma}_{\mathrm{n}, \gamma} \mathrm{IV}$ \\
\hline $\mathrm{Fe}$ & $+6.2 \%$ \\
$\mathrm{Ni}$ & $-3.1 \%$ \\
$\mathrm{Cr}$ & $+8.9 \%$ \\
$\mathrm{Mn}$ & $-19 \%$ \\
$\mathrm{Mo}$ & $-6.8 \%$ \\
$\mathrm{Na}$ & $-36 \%$ \\
\hline
\end{tabular}


The capture cross section of the coolant and shield Na is rather saall and thus less important for the neutronics of a reactor (see Table II). Cross section changes were substantial between Version $V$ and IV of ENDF/B (see Table V), mainly due to changes of the resonance parameters with $\Gamma_{Y}$ values differing by factors of 2-4. The uncertainty of $\Gamma_{\gamma}$ of the $2.85 \mathrm{keV}$ resonance contributes to the capture component of the sodium-void effect In LMFBR's, however, probably no more than $\sim 0.1 \%$ which is not considered very significant.

\section{CAPTURE IN FISSION PRODUCT NUCLEI}

The neutron fission process results in fission product nuclei with a mass distribution showing a well known double mass peak. The lighter masses are in a range of $A \sim 80-100$ and the heavier massiss are in a range of A 125-160. Many of the fission product nuclel decay with a short half-life to stable nuclei or nuclei with longer half-lives which accumulate in the fuel rods. The relative importance of these fission products as neutron capture poisons is given by the frequency of their occurrence, their halflives, and the size of their capture cross sections averaged over the reactor spectrum. The absorption of neutrons in the fission products causes a negative reactivity change which must be anticipated with a sufficient reactivity excess in the design of a reactor.

\section{Thermal Reactors}

The thermal cross sections and the resonance integral determine the neutron capture in fission product nuclei in thermal reactors. These quantities can vary by several orders of magnitude due to the statistical nature of resonance energies and neutron widths. This results in a distinct selectivity for the importance of some fission products as poisons in thermal reactors which is in contrast to fast reactors where the absorption losses are governed by the more systematic nature of the average cross sections at higher energies. The dominance of neutron capture in a few fission products in thermal reactors introduces dynamical effects which influence the operation of the reactor within the time span of the involved half-lives.

0f primary importance is the fission product ${ }^{135} \mathrm{Xe}$ which accounts for more than $50 \%$ of the fission product neutron absorption of a freshly started thermal reactor. It has a resonance at $0.084 \mathrm{eV}$, a $r_{\gamma}$ of $90.7 \mathrm{meV}$ and a reduced neutron width of $2 \mathrm{~g} \Gamma_{\mathrm{n}}^{\circ}=88.7 \mathrm{meV}$, resulting in a thermal capture cross section of $\sim 2.65 \cdot 10^{6}$ b (see Fig. 6). Although $135 \mathrm{Xe}$ constitues only $0.3 \%$ of the fission products in the $235 \mathrm{U}$ fission process, it is also enhanced from the decay of ${ }^{135} \mathrm{Te}$ which constitutes $6.1 \%$ :

$$
\begin{aligned}
& { }^{135} \mathrm{Te}(6.1 \%) \stackrel{\beta, 19 \mathrm{~s}}{\longrightarrow} 135 \mathrm{I} \stackrel{\beta, 6.6 \mathrm{~h}}{\longrightarrow} 135 \mathrm{Xe}(0.3 \%) \stackrel{\beta, 9.1 \mathrm{~h}}{\longrightarrow} 135 \mathrm{Cs} \stackrel{\beta}{\longrightarrow} 135 \mathrm{Ba} . \\
& \text { 2.6. } 20^{6} \mathrm{~b} \quad 8.7 \mathrm{~b} \quad 50 \mathrm{~b}
\end{aligned}
$$


The reactivity change is therefore determined mainly by three factors:

a) the decay of ${ }^{135} \mathrm{I}$ with a half-1ife of $6.6 \mathrm{~h}$ which causes the ${ }^{135} \mathrm{Xe}$ butld-up,

b) the decay of ${ }^{135}$ Xe with a half-Iife of 9.1 which removes some of the poison, and

c) the burn-up of ${ }^{135} \mathrm{Xe}$ during reactor operation which also removes some of this poison.

The first and the second factors are of importance for reactor shut-downs. $135 \mathrm{Xe}$ builds-up due to ${ }^{135} \mathrm{I}$ decay above the equilibrium value which it reaches due to the burn-up during reactor operation. Excess reactivity is required for restarting the reactor in order to overcome the ${ }^{135} \mathrm{Xe}$ polson, or sufficient time must elapse in order to permit the decay of $135 \mathrm{I}$ and subsequently ${ }^{135} \mathrm{Xe}$. The build-up of ${ }^{135} \mathrm{Xe}$ after reactor shut-down will be proportionally larger for higher neutron flux reactors. The excess reactivity required in a high-flux reactor because of the ${ }^{135} \mathrm{Xe}$ poison is in the order of several percent.

The neutron flux in the reactor core is much hfgher than at the reactor edge and ${ }^{135} \mathrm{Xe}$ decay and burn-up play a different role at differiat positions in the reactor. Spacial and time oscillations of the reactor power are the result of the neutron capture in ${ }^{135} \mathrm{Xe}$ : A change of the neutron flux at one point will alter the ${ }^{135} \mathrm{Xe}$ absorption which in turn will change the reactivity and amplify the original flux change. This will continue until the poison production catches up and reverses the trend.

Another fission product with a very large thermal cross section $\left(\sim 4.1 \cdot 10^{4} \mathrm{~b}\right)$ is ${ }^{149} \mathrm{Sm}$ whith is stable and occurs in the fission process with $1.1 \%$ probability. ${ }^{149} \mathrm{Sm}$ is also produced by the decay of $149 \mathrm{Pm}$ with a half-life of $53.1 \mathrm{~h}$. This long half-life requires the reactor to be built with sufficient excess reactivity in order to compensate for the ${ }^{149} \mathrm{Sm}$ build-up after shut-down as waiting for its decay would be impractical. However, the capture cross section is much smaller than for ${ }^{135} \mathrm{Xe}$ (see Fig. 6) and therefore the required excess reactivity is about one order of magnitude less.

As a reactor is operated over a longer time span other fission products accumulate and the relative importance of neutron capture in ${ }^{135} \mathrm{Xe}$ and ${ }^{149} \mathrm{Sm}$ decreases. Table VI compares the total neutron captures in some of the major fission products after $4000 \mathrm{~h}$ and after $26400 \mathrm{~h}$ of reactor operation (Schenter and England ${ }^{55}$ ). 
Table VI. Accumulated Neutron Capture Events in Individual Fission Products Relative to Total Captures in Fission Products after $4000 \mathrm{~h}$ and $26400 \mathrm{~h}$ of Reactor Operation

\begin{tabular}{rrr}
\hline Nuclide & 4000h & $\underline{26400 \mathrm{~h}}$ \\
\cline { 2 - 3 } $135 \mathrm{Xe}$ & 51.7 & 15.1 \\
$149 \mathrm{Sm}$ & 13.6 & 5.7 \\
$151 \mathrm{Sm}$ & 4.9 & 3.2 \\
$143 \mathrm{Nd}$ & 4.7 & 9.9 \\
$147 \mathrm{Pm}$ & 3.8 & 4.6 \\
$103 \mathrm{Rh}$ & 2.9 & 9.8 \\
$131 \mathrm{Xe}$ & 2.6 & 6.0 \\
$133 \mathrm{Cs}$ & 2.4 & 6.2 \\
$99 \mathrm{Tc}$ & 1.9 & 4.9 \\
$152 \mathrm{Sm}$ & 1.6 & 3.9 \\
\hline
\end{tabular}

\section{Fast Reactors}

The neutron capture cross sections of the fission product nuclei averaged over a fast-reactor spectrum are much smaller than some of their thermal cross sections and show some systematic behavior. They typically differ from each other by less than a factor of 10 . As a result, the relative importance of neutron capture is more evenly distributed over a larger number of fission products. Table VII lists the contributions of the 25 most important fission products to the total neutron absorption by fission products in a typical fast reactor. The more even distribution of capture in various fission products makes the problems of transients and restart for fast reactors negligible, and the main effect is the long term reactivity change caused by stable fission products or those with a long half-life.

The capture cross sections of the more important nuclei must be known with an uncertainty of $\sim 10 \%$ in order to calculate the bulk reactivity effect of the fission products to a required accuracy of $5-10 \%$ (Rowlands 56 ). More stringent requirements ( $\sim 5 \%$ uncertainties of cross sections) were stated recently (Hammer ${ }^{57}$ ). Some of the fission products (e.g. Nd) are used as burn-up monttors for the fuel and their cross sections are required to be known more accurately.

Measurements of capture cross sections of fission products in the fast energy range encounter various difficulties. Sultable samples are not always available, the radioactivity of even longer-living nuclei restricts the applicability of most measurement techniques. As a result experimental data for some nuclei are sparce, discrepant for others, or not avallable at a11. Figure 7 shows experimental data for the capture cross section of 
Table VII. The Twenty-five Most Important Fission Product Absorbers in Fast Reactor Cores (Schenter and England ${ }^{55}$ )

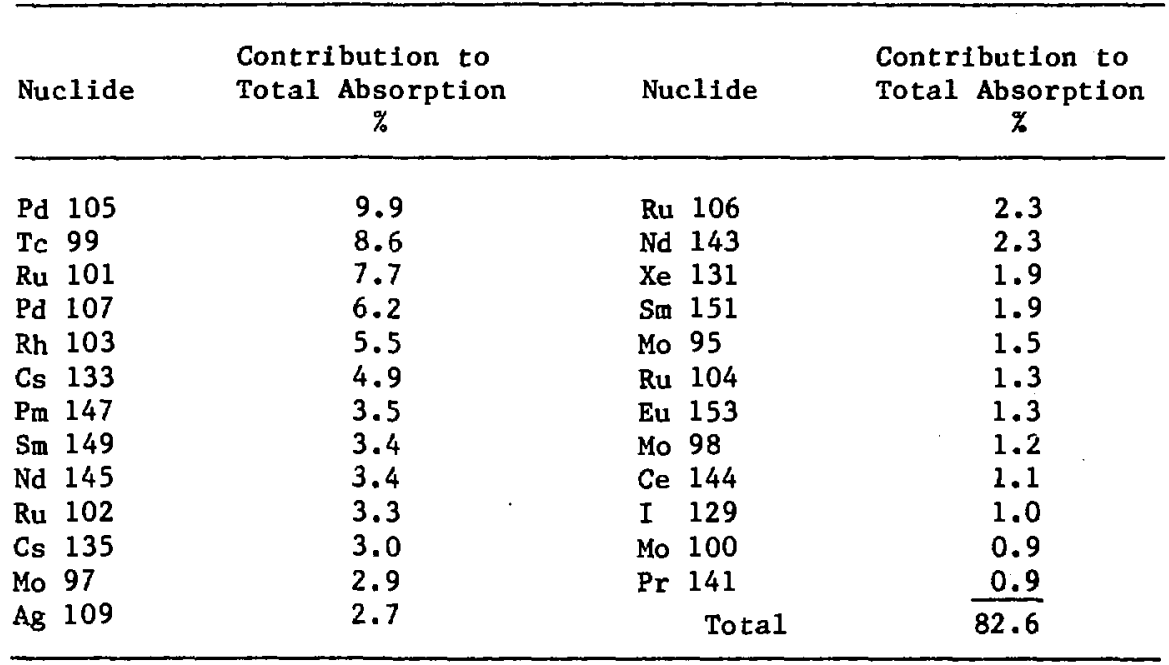

${ }^{109} \mathrm{Ag}$ which scatter by a factor of $\sim 2$. The agreement between experimental data for other nuclei may be better, with spreads of $\pm 25 \%$ and even $\pm 15 \%$ for more recent data. An example for this is given with Fig. 8 which shows the capture cross section of ${ }^{103} \mathrm{Rh}$. The complete lack of data for some nuclei and the existing discrepancies for others have encouraged the use of theoretical calculations of these cross sections in terms of the statistical model and the optical model (for example: Benzi and Reffo ${ }^{58}$, Schmittroth and Schenter ${ }^{59}$ ). Such calculated cross sections utilize experimental data for the $\gamma$-width, $\Gamma_{\gamma}$, the average level spacing, $D$, and the neutron strength function where available, or, again, systematics and calculated values. The number of parameters on which these calculations depend is substantial and good predictions can only be expected if experimental information is available to guide the normalization. This is specifically the case at higher energies ( $>1 \mathrm{MeV}$ ) where large differences must be expected between various nodel calculations which are based upon different parameter choices and approxinations. Table VIII compares the calculated neutron capture cross sections at 2 MeV for several fission product nuclei. Differences between the theoretically calculated cross sections exceed a factor of two for most nuclei and even factors of 5 and 10 occur.

The nonexistence or deficiencies of differential data and the uncertainties of theoretical calculations have led to yet another approach. Cross sections averaged over a fast reactor neutron spectrum can be measured with small samples because of the available high neutron flux. Such average cross sections can then be used to normalize theoretically calculated cross section shapes. Additional information about the cross section shape can be obtained if measurements in several reactors or test facilities were nade which have substantially different neutron spectra. 
The ENDF/B-V evaluation is based upon all three sources of information. Differential and integral (averaged) experimental data were used together with calculated cross sections in a minimization procedure (Schenter and England ${ }^{55}$ ).

The large number of fission product nuclei contributing to the poisoning of fast reactors complicates design calculations. Therefore, a lump fission product cross section is used in some calculations as an approxination. This cross section is derived by summing the Individual cross sections according to the frequency of the occurrence of specific nucle1. A sonewhat nore sophisticated approach is to take into account cross section systematics. Oddeven and even-odd nuclei have much larger cross sections than even-even nuclei. Capture in one of the former may lead to the latter and thus reduce the poisoning. Thus two lump fission product cross sections are being used in some calculations.

Table VIII, Comparison Between Different Calculated Fission Product Capture Cross Sections (in mbarn) at $2 \mathrm{MeV}$ (Iijima et al.60).

\begin{tabular}{|c|c|c|c|c|}
\hline Nuclide & Cook 61 & Benzi 58 & Lauterbach 62 & IIjima 60 \\
\hline Zr-93 & 1.43 & -- & 11.7 & 55.6 \\
\hline Mo-95 & 12.7 & 13 & 22.1 & 32.7 \\
\hline Mo-97 & 5.47 & 9.37 & 27.1 & 24.0 \\
\hline Tc-99 & 18.2 & - & 66.9 & 82.2 \\
\hline$R u-101$ & 96.1 & 26.24 & 80.3 & 67.1 \\
\hline Ru-101 & 58.3 & 90.82 & 26.1 & 73.5 \\
\hline $\mathrm{Rh}-103$ & 40.2 & 44.2 & 63.6 & 63.3 \\
\hline$R u-104$ & 15.2 & 25.0 & 26.8 & 37.5 \\
\hline$P d-105$ & 17.8 & 35.6 & 94.3 & 80.8 \\
\hline$R u-106$ & 8.11 & -- & 24.3 & 27.0 \\
\hline$P d-107$ & 43.6 & - & 91.4 & 78.1 \\
\hline$A g-109$ & 65.9 & 96.1 & 117.2 & 112.2 \\
\hline$I-129$ & 21.3 & - & 39.6 & 56.7 \\
\hline $\mathrm{Xe}-131$ & 17.2 & 16.1 & 31.5 & 28.7 \\
\hline $\mathrm{Cs}-133$ & 10.7 & 19.2 & 45.4 & 30.7 \\
\hline $\mathrm{Nd}-143$ & 10.8 & 13.1 & 17.6 & 120.5 \\
\hline$N d-144$ & 30.8 & 28.3 & 65.8 & 34.2 \\
\hline $5 m-147$ & 24.0 & 36.9 & 71.1 & 82.7 \\
\hline$S m-149$ & 31.1 & 47.7 & 135.0 & 238.1 \\
\hline Sm-151 & 137.1 & 50.7 & 194.2 & 249.1 \\
\hline
\end{tabular}




\section{THE PRODUCTION OF HIGHER ACTINIDES}

Neutron capture in heavy fissile and fertile elements plays a predoninant role in the build-up of transactinides in reactors. Other factors are radioactive decay, $(n, 2 n)$, and fission reactions. A typical build-up chain is shown in Fig. 9. Nuclear data and specifically neutron capture cross sections are required to evaluate the various effects of these higher transactinides for different aspects of the nuclear technology which become increasingly important. The overwhelming concern is the disposal of the transactinides as waste, however, other aspects as for example the influence of the actinides on the reactor reactivity and breeding gain are of interest. A positive element of the creation of the higher actinides is the usefulness of several nuclei for a varlety of applications, e.g. in medical, industrial and agricultural areas.

Problems relating to the higher actinides can be divided into two major groups :

1. The changes of the neutronics of the reactor core which result from the changes of the isotopic compasition of the fertile and fissile materials, and affect the reactivity, reactor power, and breeding gain.

2. Problems created by the higher actinides for other parts of the nuclear fuel cycle. These include fuel handling, transport and reprocessing, waste management, subcritical reactivity during refueling, and fuel fabrication from recycled fissile/ferille materials.

A distinct difference exists between the higher plutonium isotopes ${ }^{240} \mathrm{Pu},{ }^{241} \mathrm{Pu}$, and $242 \mathrm{Pu}$ which contribute a reactivity loss of $2 \%$ and the other higher transactinides. The former are the Inevitable result of LWR reprocessed fuel. Concentrations of $240 \mathrm{Pu}$ and ${ }^{241} \mathrm{Pu}$ exceed other higher transactinides by at least one or two orders of magnitude and their nuclear cross section data are usually matching the primary fuel nuclei in importance. The concentrations of ${ }^{240} \mathrm{Pu}$ and ${ }^{241} \mathrm{Pu}$ in recycled fuel from LWR's and LMFBR's are somewhat different (see Table IX), and thus, so is the Importance of their nuclear data. For both types of reactors the higher plutonium, americium, curium, and californium isotopes have an insignificant overall impact on the neutronics, although effects for Individual isotopes are none - zero. The effects on the reactivity, internal breeding gain, and total power of a fast reactor due to the higher transactinides

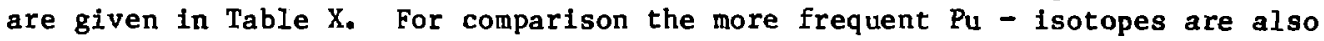
1 isted. 
Table IX. Comparison of the Yearly Production of Transactinides in LWR's and LMFBR's (Kuesters and Lalovie ${ }^{63}$ ).

\begin{tabular}{lcc}
\hline & \multicolumn{2}{c}{ kg/year } \\
Isotope & $\begin{array}{c}\text { LWR } \\
(\mathrm{U}-\text { fueled })\end{array}$ & \\
\hline & \multicolumn{2}{c}{ LMFBR } \\
Pu 236 & 0.02 & \\
Pu 238 & 4.5 & 0.002 \\
Pu 239 & 145 & 15 \\
Pu 240 & 59 & 1318 \\
Pu 241 & 27 & 441 \\
Pu 242 & 9 & 120 \\
An 241 & 2 & 75 \\
An 242M & 0.01 & 11 \\
An 243 & 2.5 & 0.2 \\
Cm 242 & 0.09 & 5.6 \\
Cm 243 & 0.02 & 0.3 \\
Cm 244 & 0.83 & 0.02 \\
\hline
\end{tabular}

Table X. Effect of the Transactintdes on Fast Breeder Parameters (Barre and Bouchard ${ }^{64}$ ).

\begin{tabular}{lccc}
\hline Nuclide & $\begin{array}{c}\text { Internal Breeding } \\
\text { Gain }\end{array}$ & $\begin{array}{c}\text { Total } \\
\%\end{array}$ & $\begin{array}{c}\text { Power } \\
\text { U-232 }\end{array}$ \\
Np-237 & 0 & 0 & 0 \\
Np-239 & 0.005 & 0 & 0.1 \\
Pu-236 & 0 & 0 & 0.1 \\
Pu-238 & 0 & 0 & 0 \\
Am-241 & -0.003 & 0.5 & 0.3 \\
Am-242M & 0.023 & 0.2 & 0.6 \\
Am-243 & -0.007 & 0.3 & 0.1 \\
Cn-242 & 0.004 & 0.1 & 0.5 \\
Cm-243 & -0.001 & 0.1 & 0 \\
Cm-244 & 0 & 0 & 0 \\
\hline & 0 & 0.1 & 0 \\
Total & +0.021 & 1.3 & 1.7 \\
Pu-240 & 0.115 & 6.3 & 6.4 \\
Pu-241 & -0.143 & 7.8 & 4.0 \\
Pu-242 & -0.001 & 0.7 & 1.1 \\
\hline
\end{tabular}


Measurements of capture cross sections of the higher actinides are troubled by two major problems. The first is the scarcity of suitable samples. Substantially larger amounts are needed for capture measurements than for fission or total cross section experiments. Exceptions are the thermal cross sections which are usually large and thus require smaller sample masses, and integral values which can be carried out at higher neutron flux levels than available for differential cross section experiments. The second problem is the limited applicability of available measurement techniques. High spontaneous fission decay and $\alpha$-decay rates, or fission competition make measurements very difficult.

The thermal capture cross sections and the infinite dilute resonance integrals are usually known at about the requested uncertainty levels. A surprising exception is the resonance integral of $240 \mathrm{Pu}$ which is sought to be known to $3 \%$ but is uncertain by $\sim 17 \%$ (Benjamin ${ }^{65}$ ). The low energy cross section of $240 \mathrm{Pu}$ is dominated by a $10^{5} \mathrm{~b}$ resonance at $1 \mathrm{eV}$ which contributes $~ 99 \%$ of the thermal cross section. This resonance was excluded in more recent measurements (because it would require special samples) and its resonance parameters $\left(\Gamma_{\gamma}, \Gamma_{n}\right)$ are known from older measurements with $\sim 10 \%$ uncertainty (Weston ${ }^{66}$ ). The well known the mal cross section may be used as a constraint for a resonance parameters fit and reduce the uncertainty in the resonance range (Thompson and Leonard67). Data in the unresolved resonance and higher $\mathrm{keV}$ energy range, important for fast reactors, agree within typically $\sim 15 \%$. The measurements by Weston and Todd 68 are in best agreement with the average resonance parameters.

Capture in ${ }^{240} \mathrm{Pu}$ leads to ${ }^{241} \mathrm{Pu}$ which is a good reactor fuel and its fission cross section and decay to $241 \mathrm{Am}$ are more important for reactor neutronics than neutron capture. However, neutron capture in $241 \mathrm{Pu}$ and in $241 \mathrm{Am}$ lead to nuclei which create fuel handling $\left({ }^{242} \mathrm{Cm},{ }^{244} \mathrm{Cm}\right.$ and $252 \mathrm{Cf}$, which are neutron emitters) and waste management problems.

With the exception of ${ }^{241} \mathrm{Pu},{ }^{242} \mathrm{Pu}$ and ${ }^{241} \mathrm{Am}$, few differentlal data have been measured except at low energies in the resolved resonance energy range. Therefore, evaluated data must rely heavily on theoretical calculations to provide capture cross sections in the higher keV energy range. Experimental resonance parameters and integral values are used for normalization; and nuclei for which experimental values exist provide test cases for such calculations. Figure 10 shows, for example a theoretically calculated capture cross section for $240 \mathrm{Pu}$. Agreement with experimental data is within the $\pm 15 \%$ data scatter. 
Figure Captions

Fig. 1. Experimental Results for the Thermal Neutron Capture Cross Section of $238 \mathrm{U}$. The ENDF/B-V Value is also shown.

Fig. 2. Comparison of Experimental Data with a Theoretically Calculated Cross Section of $238_{U}(u, \gamma)$.

Fig. 3. Fluctuations of the ${ }^{238} \mathrm{U}$ Neutron Capture Cross Section in the 10 $90 \mathrm{keV}$ Region. The Data by DeSaussure et a1. ${ }^{30}$ Averaged with Various Resolutions Relative to a Smoothly Averaged Cross Section are Shown.

Fig. 4. Comparison of Recent Experimental Data with a Theoretically Ca1culated Cross Section of ${ }^{232} \mathrm{Th}(n, \gamma)$.

Fig. 5. The Neutron Capture Cross Sections of ${ }^{56} \mathrm{Fe},{ }^{58} \mathrm{Ni},{ }^{60} \mathrm{NI}$ ane ${ }^{61} \mathrm{Ni}$. Narrow p-Wave Resonances with Large Peak Cross Sections and Wide S-Wave Resonances are Evident. The Odd-Mass Nuclet $61_{\mathrm{NI}}$ has a Substantially Larger Cross Section than the Even-Mass Isotopes.

Fig. 6. The Neutron Capture Cross Sections of the Fission Product Poisons $135 \mathrm{Xe}$ and $149 \mathrm{Sm}$ in the Thermal Energy Range.

F1g. 7. Experimental Data, a Theoretical Calculation, and two Evaluations of the Neutron Capture Cross Section of $109 \mathrm{Ag}$. Discrepancles Exceeding a Factor of Two are Obvious in Both, Experimental Results and Evaluations.

Fig. 8. More Recent Experimental Results for the Fast Neutron Capture Cross Section of $103_{\mathrm{Rh}}$. The Data are in a \pm 15 Percent Range, thus Falling Short of the \pm 7 Percent Required for Technological Applications. Cross Section Values, Multiplied by the Squareroot of the Energy, are Shown.

Fig. 9. A Schematic of the Bulld up of the Higher Actinides. Neutron Capture is Indicated by Horizontal Double-Solid Arrows.

Fig. 10. The Neutron Capture Cross Section of ${ }^{240} \mathrm{Pu}$. Experimental Data are Shown Along with a Theoretical Calculation (Solid Line) and the Evaluation of ENDF/B-V (Dotted Line). 
Capture Cross Section, b

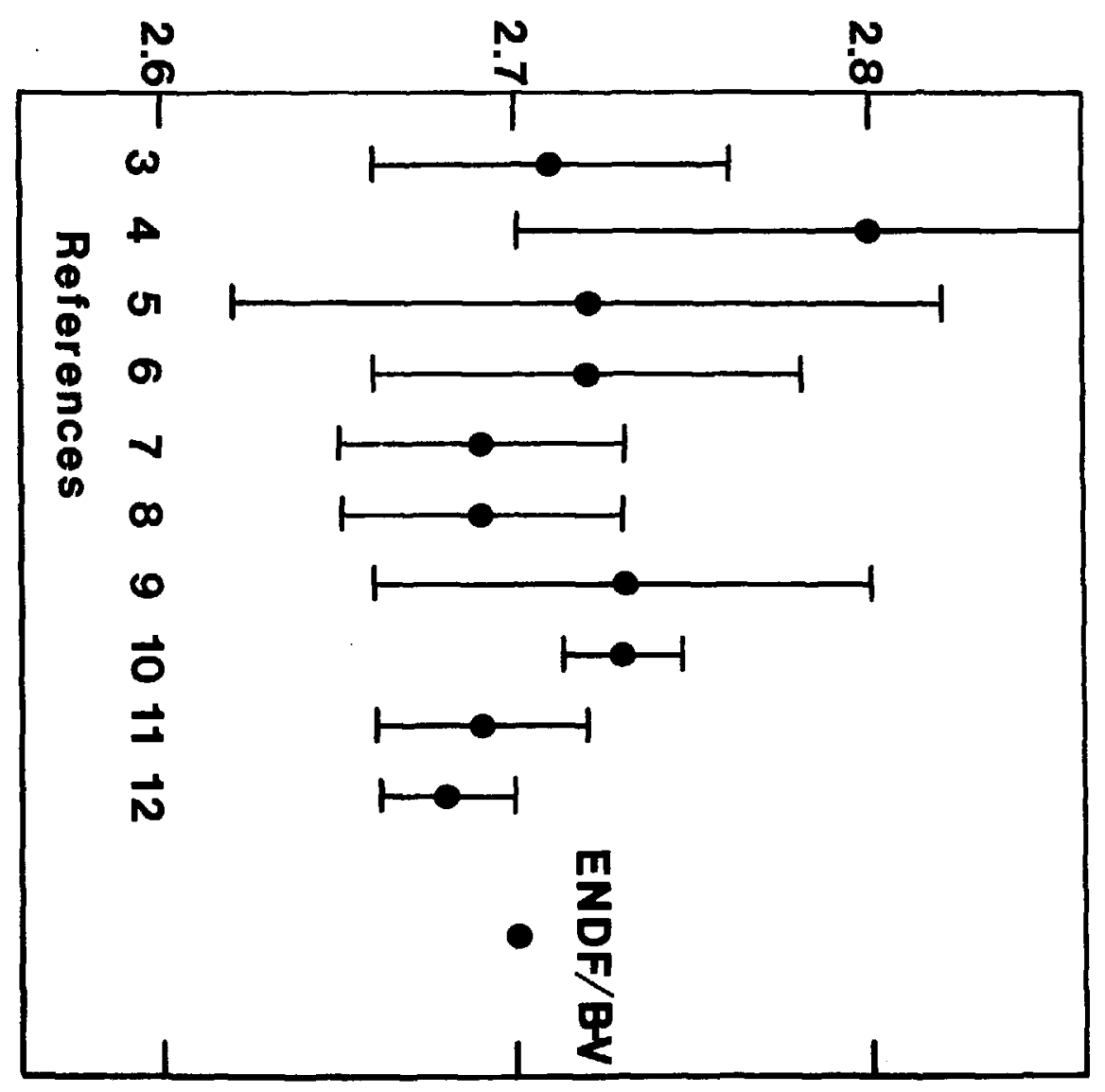




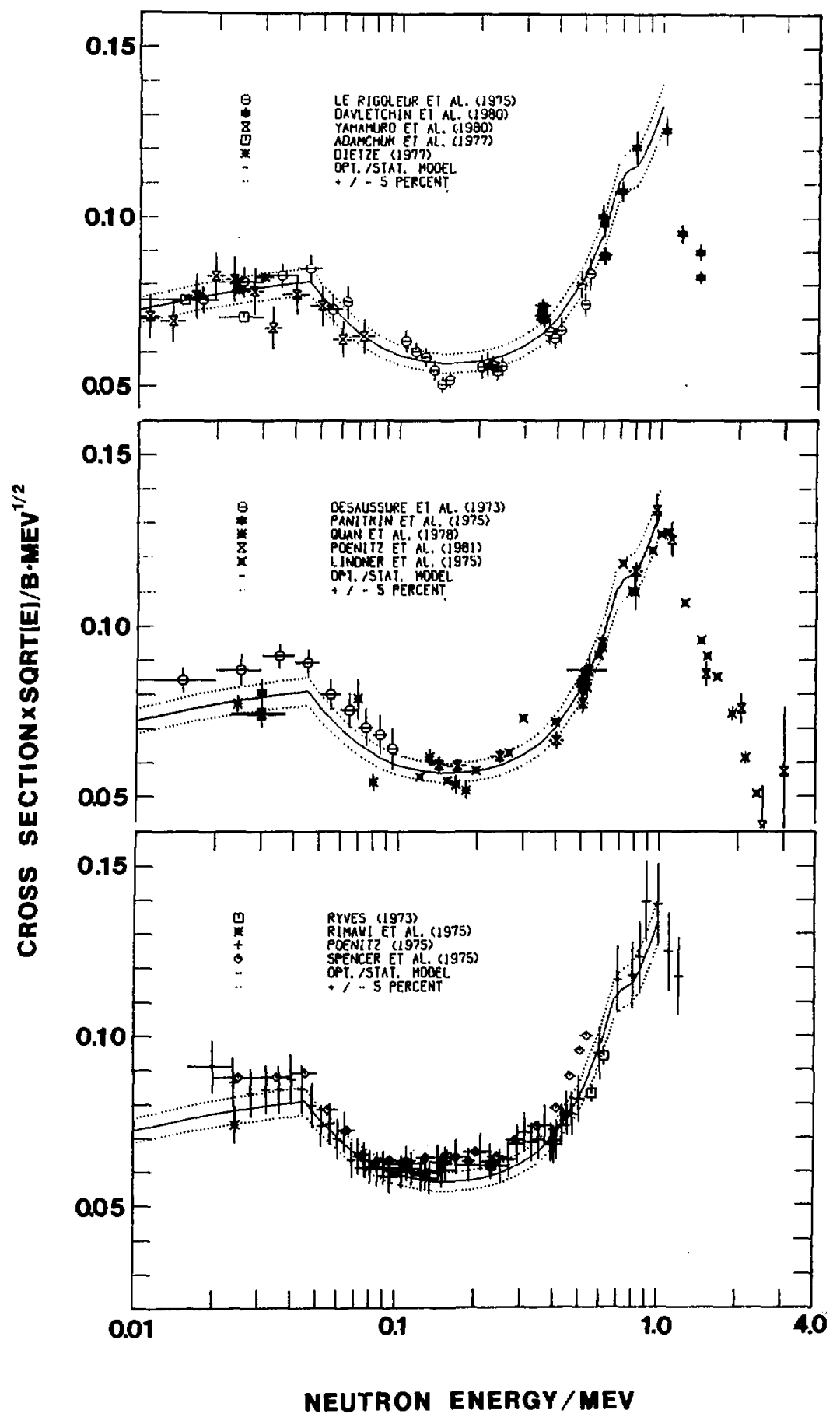




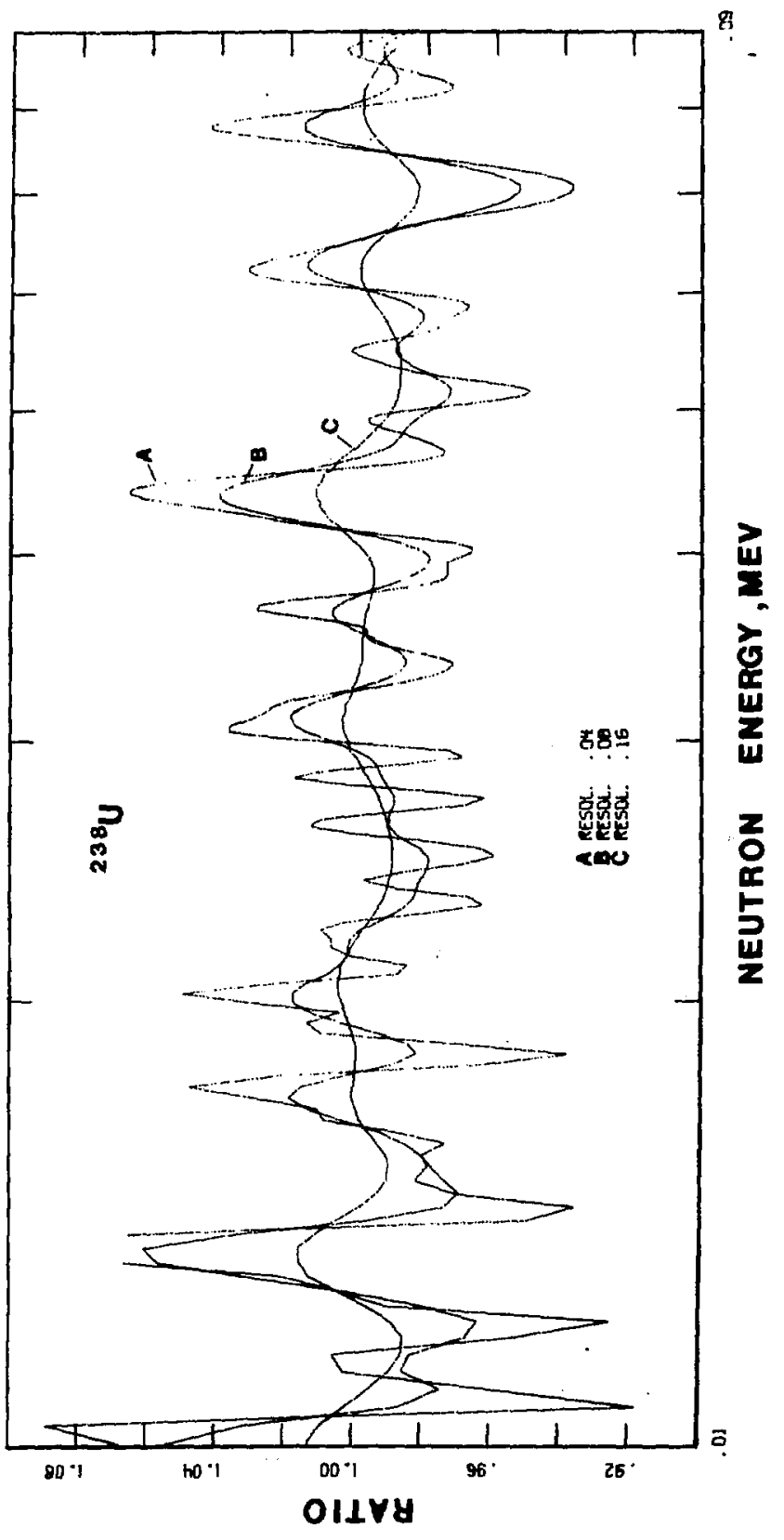




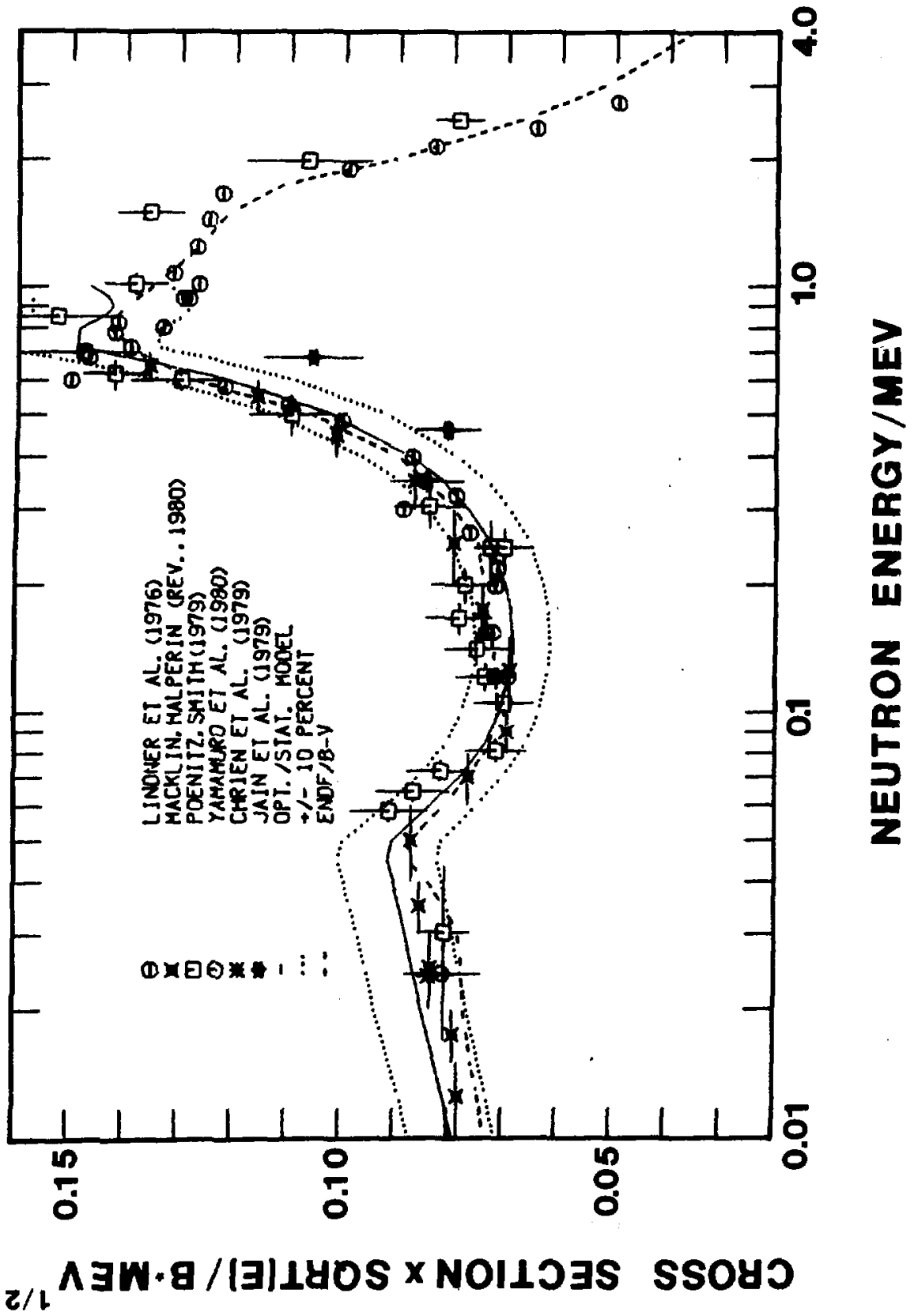



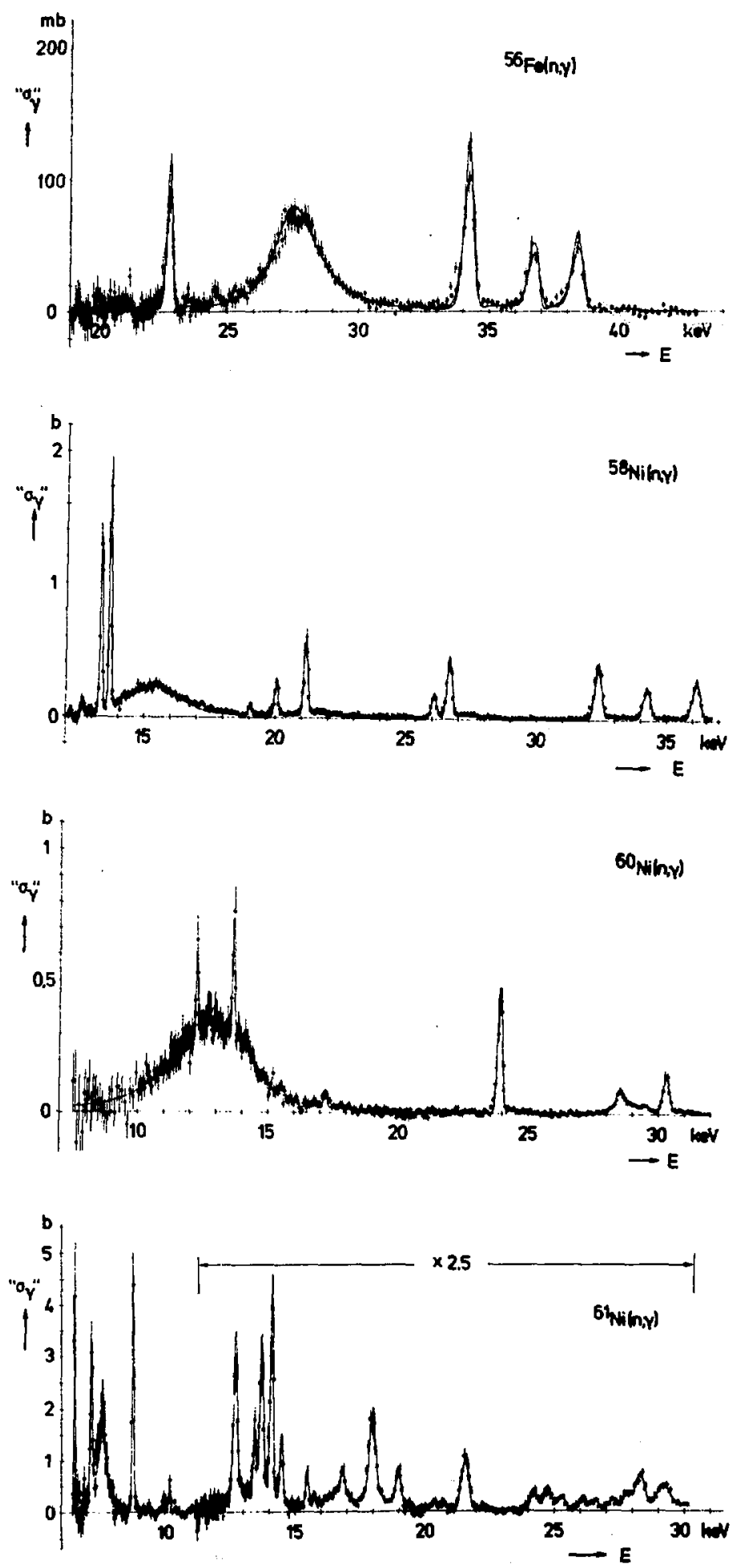


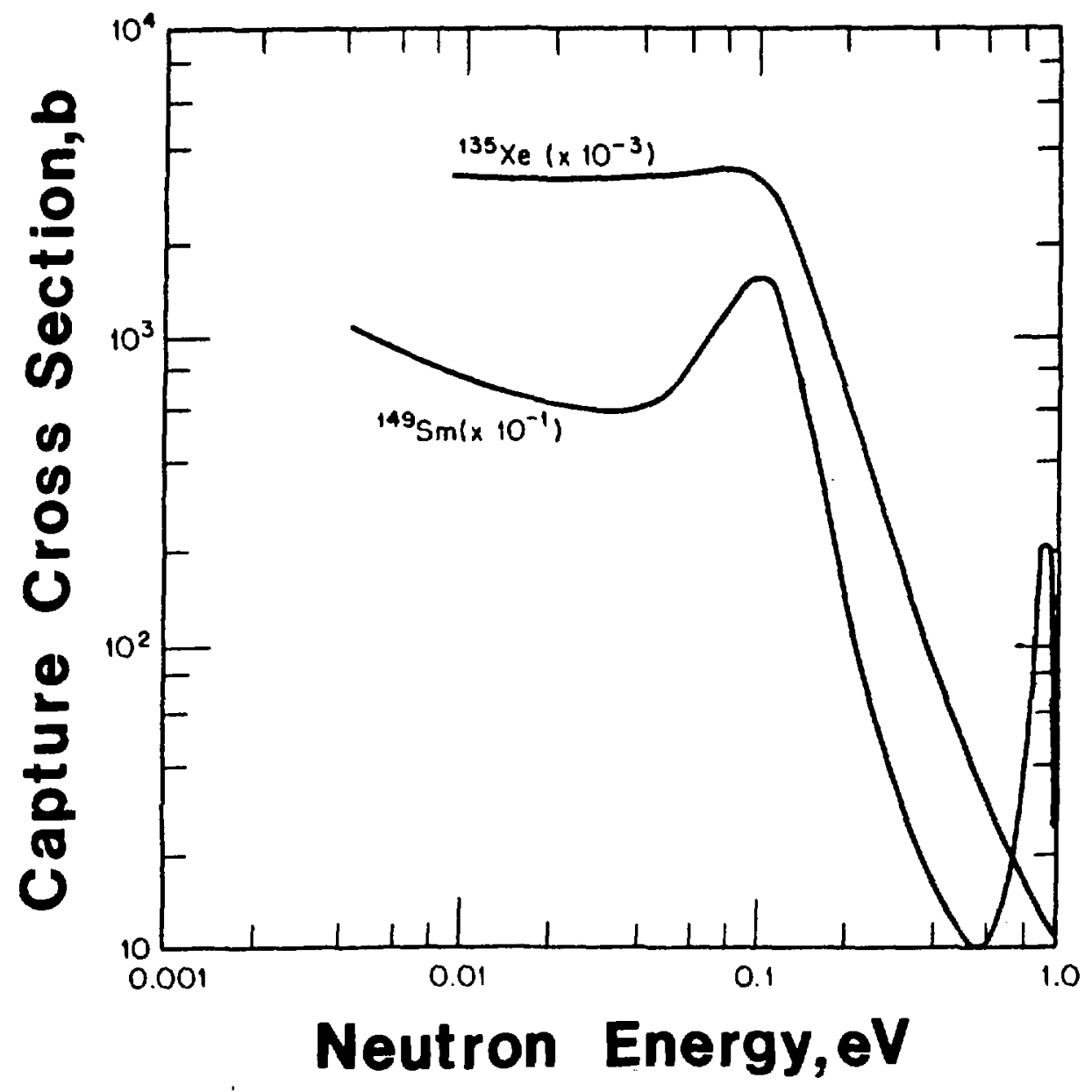




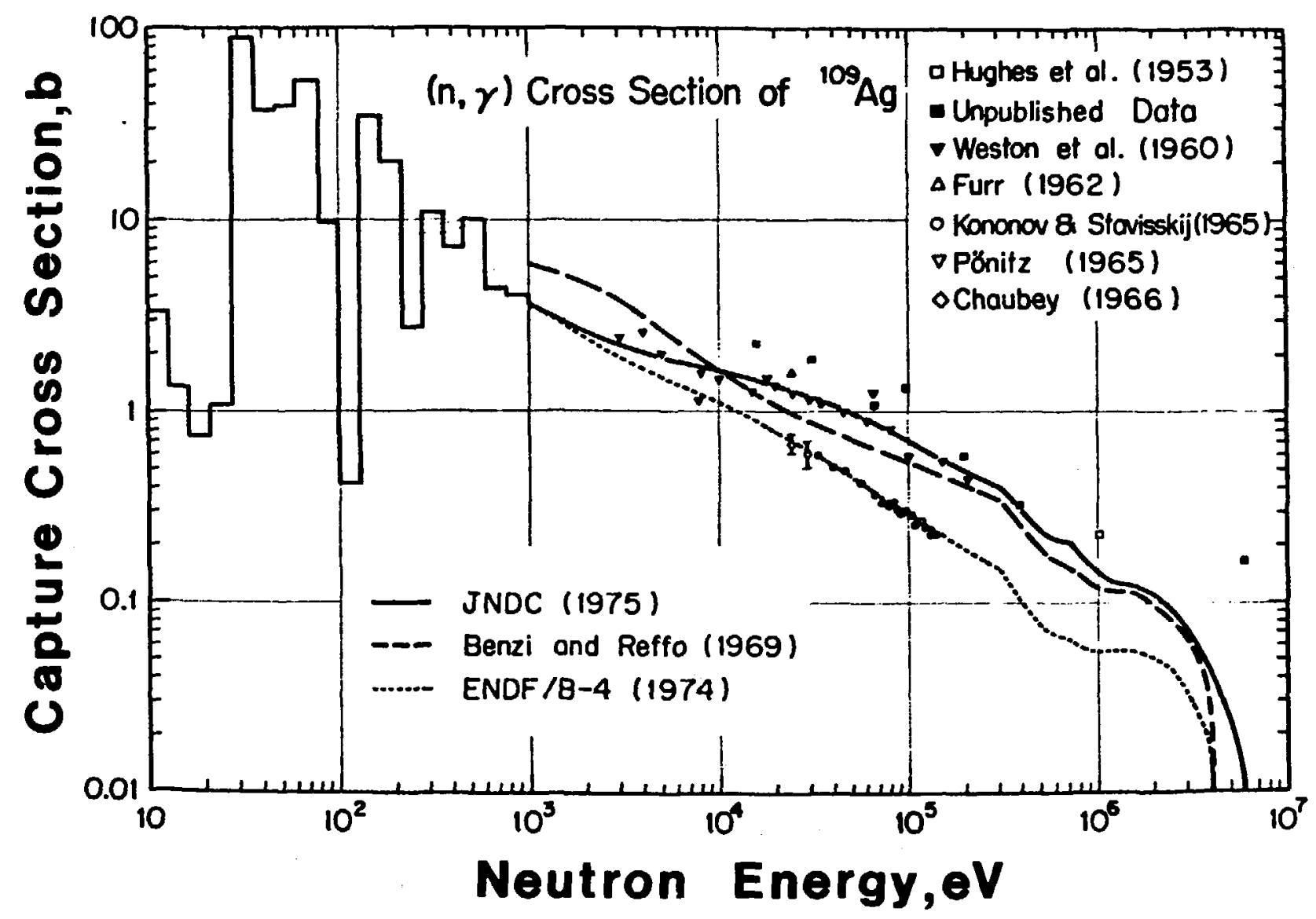




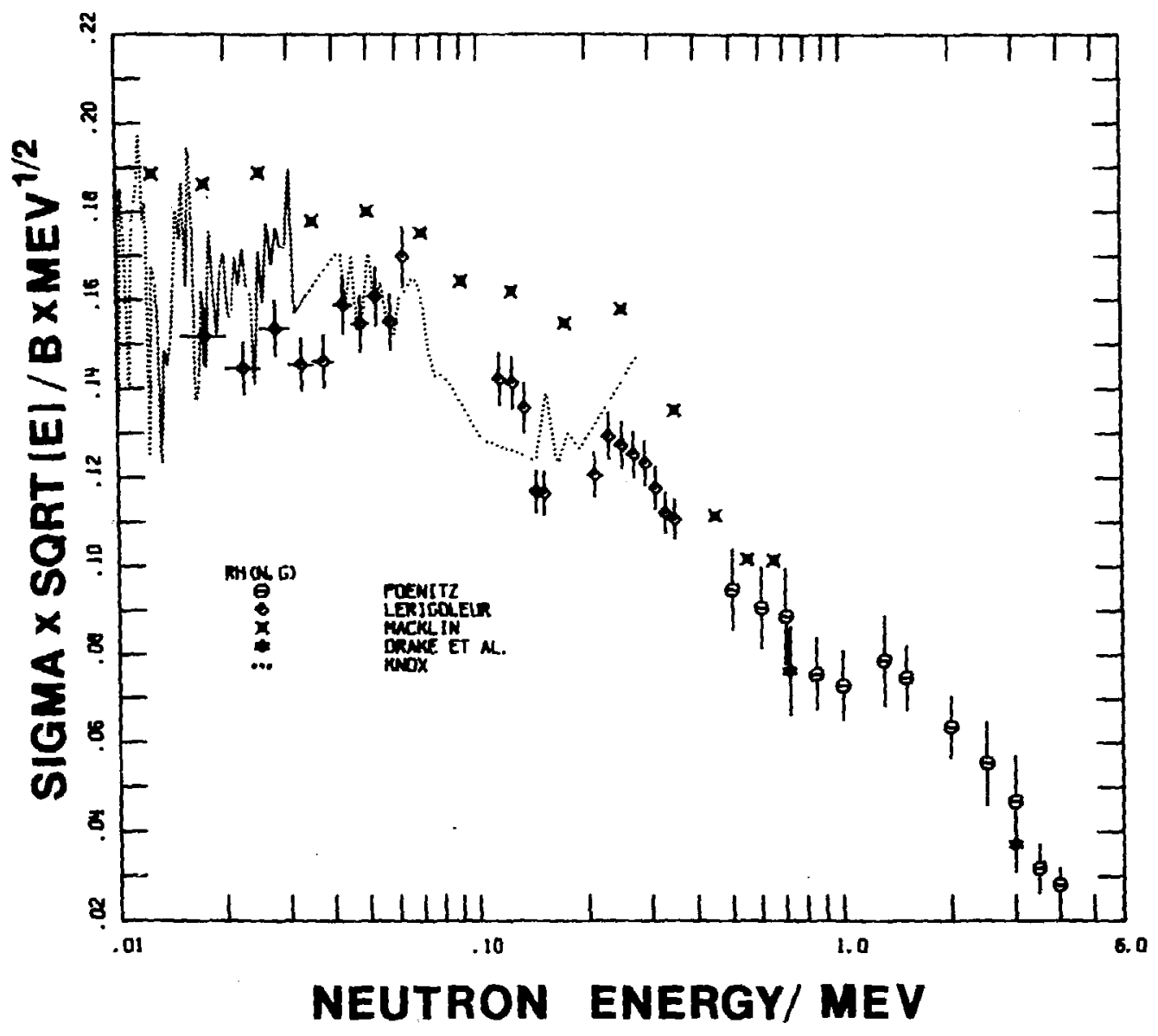




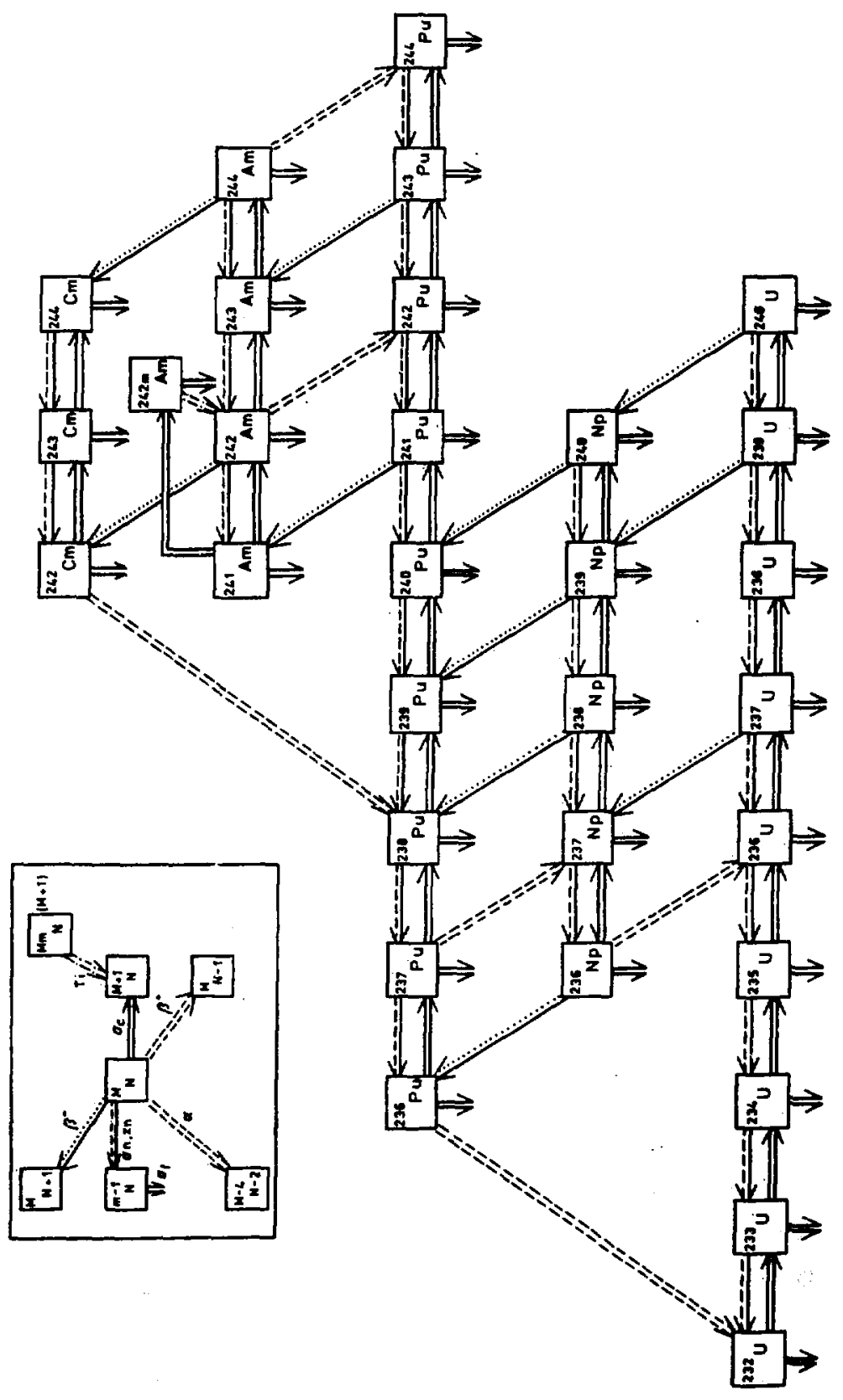




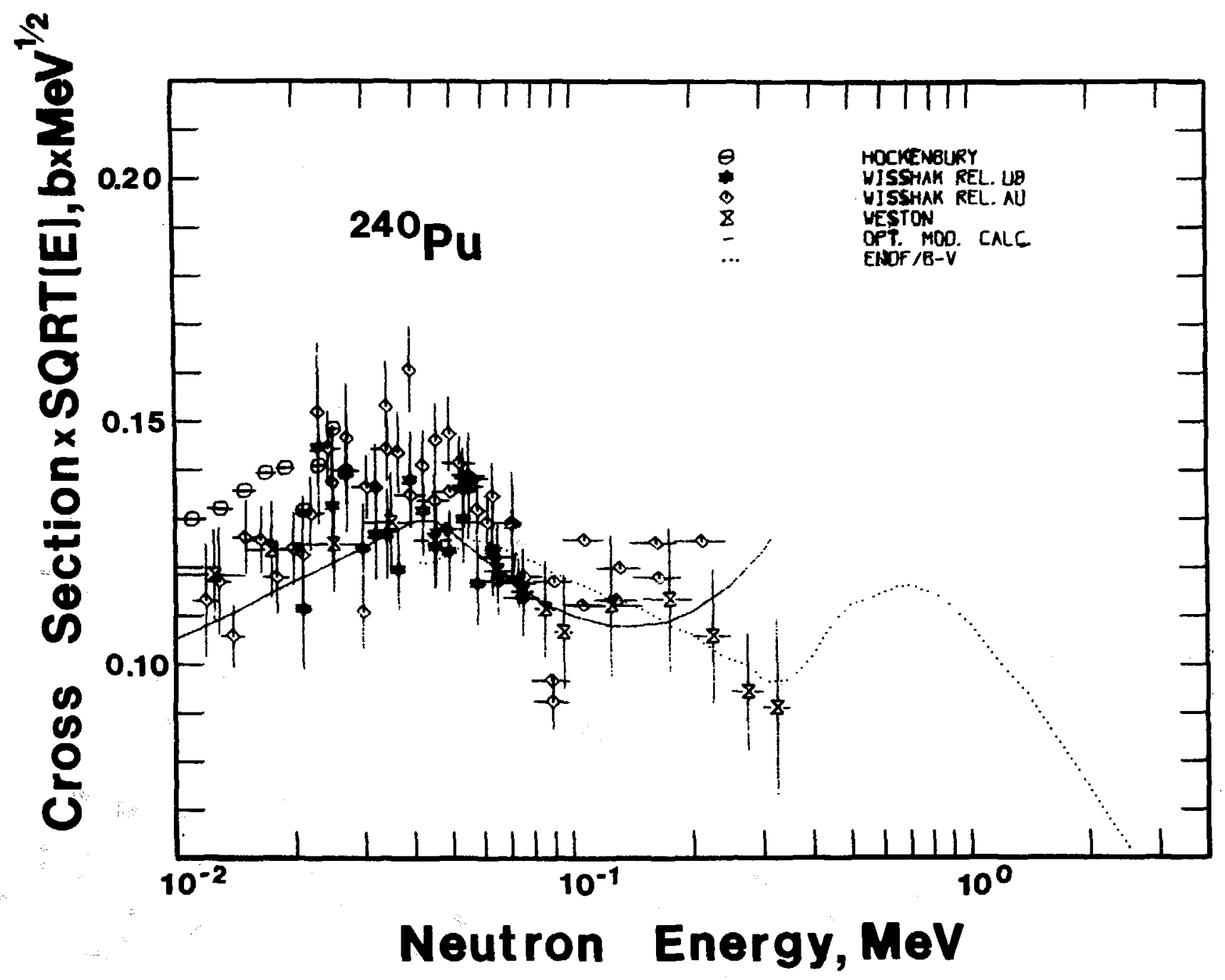




\section{$\underline{\text { References }}$}

1. L. G. LeSage, R. D. McKnight, D. C. Wade, K. E. Freese, and

P. J. Collins, Proc. NEACRP/IAEA Specialists Meeting on Int'1

Comparison Calculation of a Large Sodium-Cooled Fast Breeder

Reactor, Argonne National Laboratory Report, ANL-80-78, 1978.

2. Y. I. Chang and C. E. Till, Fast Breeder Reactor Studies, Argonne National Laboratory Report, ANL-80-40, p. 31 (1980).

3. S. P. Harris, D. Rose, and H. D. Schroeder, Argonne National Laboratory Report, ANL -LAT-109, (1954).

4. P. A. Egelstaff, J. Nucl. Energy 1, 92 (1954).

5. V. S. Croker, J. Nucl. Energy 1, 234 (1955).

6. V. G. Sma11, J. Nuc1. Energy_1, 319 (1955).

7. S. J. Coking and P. A. Egelstaff, U. S. Naval Radiologial Defense Laboratory, Report NRDC-84, Part 2 (1955).

8. P. A. Egelstaff and J. W. Ha11, in same rpeort as Ref. 24.

9. H. Palevsky, Proc. Conf. on Peaceful Use of Atomic Energy, Geneva $\underline{4}$, $147(1955)$.

10. C. B. Bighan, P. W. Durham, and J. Ungrin, Can. J. Physics 47, 1317 (1969).

11. J. B. Hunt, J. C. Robertson, and T. B. Ryves, Nucl. Energy 23, 705(1969).

12. W. P. Poenitz, L. R. Fawcett, Jr., and D. L. Smith, Nuc1. Sc1. \& Eng. 78, $239(1981)$.

13. E. T. Tomlinson, G. deSaussure, and C. R. Weisbin, "Sensitivity Analysis of TRX-2 Lattice Parameters with Emphasis on Epithermal $238_{U}$ Capture", Electric Power Research Institute Report, EPRI NP-346 (1977).

14. F. J. McCrosson and J. Hardy, Jr., Proc. Seminar on $238_{U}$ Resonance Capture, Brookhaven National Laboratory Report, BNL-NCS-50451, p. 13 (1975).

15. D. K. Olsen, Nucl. Sc1. \& Eng. 62, 479(1977).

16. H. I. Liou and R. E. Chrien, Nucl. Sci. Eng. 62, 463(1977).

17. F. Poortmans et al., "Neutron Resonance Parameters for $238_{U}$ ", Int' 1 Conf. on Neutron Physics, IV, Kiev (1977). 
18. R. C. Block, D. R. Harris, K. Kobayshi and S. H. KIn, ${ }^{238} \mathrm{U}$ Resonance Self-Indication Capture Measurenents and Analysis", Electric Power Research Institute Report NP-996, (1979).

19. R. C. Welsbin et al., Nucl. Sc1. Eng. 66, 307(1978).

20. L. N. Usachev and Yu. G. Bobkov, Intern. Nucl. Data Comittee Report, INDC (CCP) - 19U (1972).

21. W. P. Poenitz, "Fast Neutron Capture Cross Sections of Importance in Technological Applications", Conf. on Nuclear Cross Sections for Technology, NBS Spectal Publication 594, 368(1979).

22. L. G. LeSage and R. D. McKnight, "Discussion of Integral Experiment C/E Discrepancies", Conf. on Nuclear Cross Sections for Technology, NBS Special Publication 594, 297(1979).

23. E. M. Bohn, "The Central Worth Discrepancy in Three Fast Reactor Benchmark Critical Assenblies", Argonne National Laboratory Report, ANL $-75-14$ (1975).

24. C. LeRigoleur et al., Proc. Conf. Nucl. Cross Sections and Technology, Washington, D.C., March 3-7, 1975, NBS Speclal Publication 425, 2, 953 (1975).

25. B. L. Quam et al., Trans. An. Nucl. Soc. 23, 498(1976).

26. 6. P. Poenitz, Nucl. Sc1. Eng. 57, 300(1975).

27. M. Lindner et al., Nucl. Sc1. Eng. 59, 381(1976).

28. A. N. Davletshin et al., Proc. Third National Soviet Conf. on Neutron Physics, Kiev, May 26-30, 1975, 4, 109(1975).

29. T. B. Ryves et a1., J. Nucl. Energy 27, 519(1973).

30. G. DeSaussure et al., Nucl. Sc1. Eng. 51, 383(1973).

31. W. P. Poenttz and D. L. Salth, "Fast Neutron Radiative Capture Cross Section of ${ }^{232} \mathrm{Th}$ ", Argonne National Laboratory Report, ANL-NDM-42 (1978).

32. R. E. Chrien, H. I. Lion, M. J. Kenny, and M. L. Stelts, Nucl. Sc1. \& Eng. 72, 202(1979).

33. J. J. Ullo, J. Hardy, Jr., and N. M. Steen, "Review of ThorIum-U233 Cycle Thermal Reactor Benchnark Studies", Symp. on Nuclear Data Problens for Thermal Reactor Applications", Electric Power Research Institute Report, EPRI NP-1098, p. 9-1, (1979).

34. H. Derrien, "Evaluation of ${ }^{232} \mathrm{Th}$ Resonance Paraneters", Specialists Meeting on Resonance Parameters of Fertlle Nuclei and $239 \mathrm{Pu}$, Nuclear Energy Agency Nuclear Data Comnittee Report, NEANDC (E)-163 U, 73(1974). 
35. R. L. Macklin and J. Halperin, Nucl. Sci. Eng. 64, 849(1977), and private communication, (1980); also Nucl. Sci. \& Eng., to be published (1981).

36. N Yamamuro et a1., J. Nuc1. Sci. and Technology 17, 582(1980).

37. N. E. Holden and J. R. Stehn, Symp. on Nucl. Data Problems for Thermal Reactor Applfcations, Electric Power Research Institute Report EPRI NP-1098, 1979, p. 1-7.

38. M. G. Schomberg, M. G. Sowerby and F. W. Evans, "A New Method of Measuring $\alpha(E)$ for ${ }^{239} \mathrm{Pu}^{\circ}$, Proc. Symp. on Fast Reactor Physics, Int. Atomic Energy Agency Report STI/PUB/165 (1968).

39. M. G. Schomberg and M. G. Sowerby, EANDC(UK)-100 AL (1968).

40. R. Gwin et al., Nucl. Sc1. Eng., 59, 79(1976).

41. Yu. V. Ryabov, So Don-sik, N. Chirov and N. Yaneva, Atomnaya Energ. 24, 354(1968).

42. G. V. Muradyan et a1., Proc. Conf. Nuclear Cross Sections for Technology, Knoxville, (1979), NBS Special Publication 594, 488(1980).

43. H. Takano and Y. Ishiguro, "Comparison of Effective Capture Cross Sections and Doppler Coefficients for Structural Materials", Proc. NEACRP/NEANDC Specialists Meeting on Neutron Capture in Structural Materials, Nuclear Research Center Karlsruhe Report, KFK 2046, 317(1975).

44. M. C. Moxon, D. B. Gayther, and M. G. Sowerby, "Some Problem Areas in Capture Cross Section Measurements", see Ref. 43 p. 73.

45. S. P. Kapchigashev, Y. P. Popov, Sov. J. At. En., 16, 306(1960).

46. B. C. Diven, J. Terrel1, and A. Hemmendinger, Phys. Rev., 120, 556(1960).

47. R. G. Stieglitz, Nucl. Phys. Al63, 592(1971).

48. H. Beer and R. R. Spencer, Nucl. Phys. A240, 29(1975),

49. B. J. Allen, A. R. De L. Musgrove, J. W. Boldeman and R. L. Macklin, Nucl. Phys. A283, 37(1977); Nucl. Phys. A269, 408(1976).

50. A. Brusegan, F. Corvi, G. Rohr, R. Shelley, T. VanderVeen, E. Cornelis, C. Jungmann, L. Mewissen, and F. Poortmans, "High Resolution Cross Section Measurements of Structural Materials", NEANDC/NEACRP Specialists Meeting on Neutron Data of Structural Materials for Fast Reactors, Geel, EURATOM (1979).

51. D. B. Gayther, B. Thom, M. C. Moxon, and J. E. Jolly, "Capture Cross Sections of Structural Materials Measured with the Harwell Large Liquid Scintillator", see Ref. 50 (1979). 
52. G. D. James and D. B. Syme, "Transmission Measurements on the Harwell Synchrocyclotron", see Ref. 50 (1979).

53. These values were cited in varlous papers presented at the NEANDC/NEACRP Specialists Meeting on Neutron Data of Structural Materials for Fast Reactors, Geel, EURATOM (1979).

54. E. Pennington, Argonne National Laboratory, private communication (1980).

55. R. E. Schenter and T. R. England, "ENDF/B-V Fission Product Cross SEction Evaluations", Proc. Specialists Meeting on Neutron Cross Sections of Fission Product Nuclei, Bologna, NEANDC(E) 209L, 253(1979).

56. J. L. Rowlands, "Nuclear Data for Reactor Design, Operation and Safety", Proc. Conf, on Neutron Physics and Nuclear Data, Harwell, 7(1978).

57. Ph. Hammer, Proc. Conf. on Neutron Physics and Nuclear Data, Harwell, p. 551, (1978).

58. V. Benzi and G. Reffo, ENEA Neutron Data Compllation Center Newsletter No. 10, (1969).

59. F. Schmittroth and R. E. Schenter, Handford Engineering Developaent Laboratory Report, HEDL TME 73-63 (1973).

60. S. Iijima, T. Naragawa, Y. Kikuchi, M. Kawal, H. Matsunobn, K. Maki and S. Igaras1, J. Nuclear Sc1. Technology 14, 161(1977).

61. J. L. Cook, Austraian Atomic Energy Commission Report, AAEC/TM 549, (1970).

62. G. Lauterbach, US-EURATOM Fast Reactor Exchange Program Report RCN-191 (1973).

63. H. Kuesters and $M$. Lalovic, Proc. Transactinium Isotope Nuclear Data, IAEA-186, Vol. I, 139, Karlsruhe (1975).

64. J. Y. Barre and J. Bouchard, Proc. Transactinium Isotope Nuclear Data, IAEA-186, Vol. I, 113, Karlsruhe (1975).

65. R. W. Benjamin, Proc. Transactinium Isotope Nuclear Data, IAEA-186, Vol. II, 1, Karlsruhe (1975), Proc. Nuclear Data Problems for Thermal Reactor Applications, EPRI NP-1098, 12-1, BNL (1978).

66. L. W. Weston, Proc. Specialists Meeting on Nuclear Data of Plutonium and Americium Isotopes for Reactor Applications, BNL 50991, 1(1978).

67. J. K. Thompson and B. R. Leonard, private communication to L. W. Weston, see $\operatorname{Ref} .66$.

68. L. W. Weston and J. H. Todd, Nucl. Se1. \& Eng. 65, 454(1978). 